BMC

Genomics

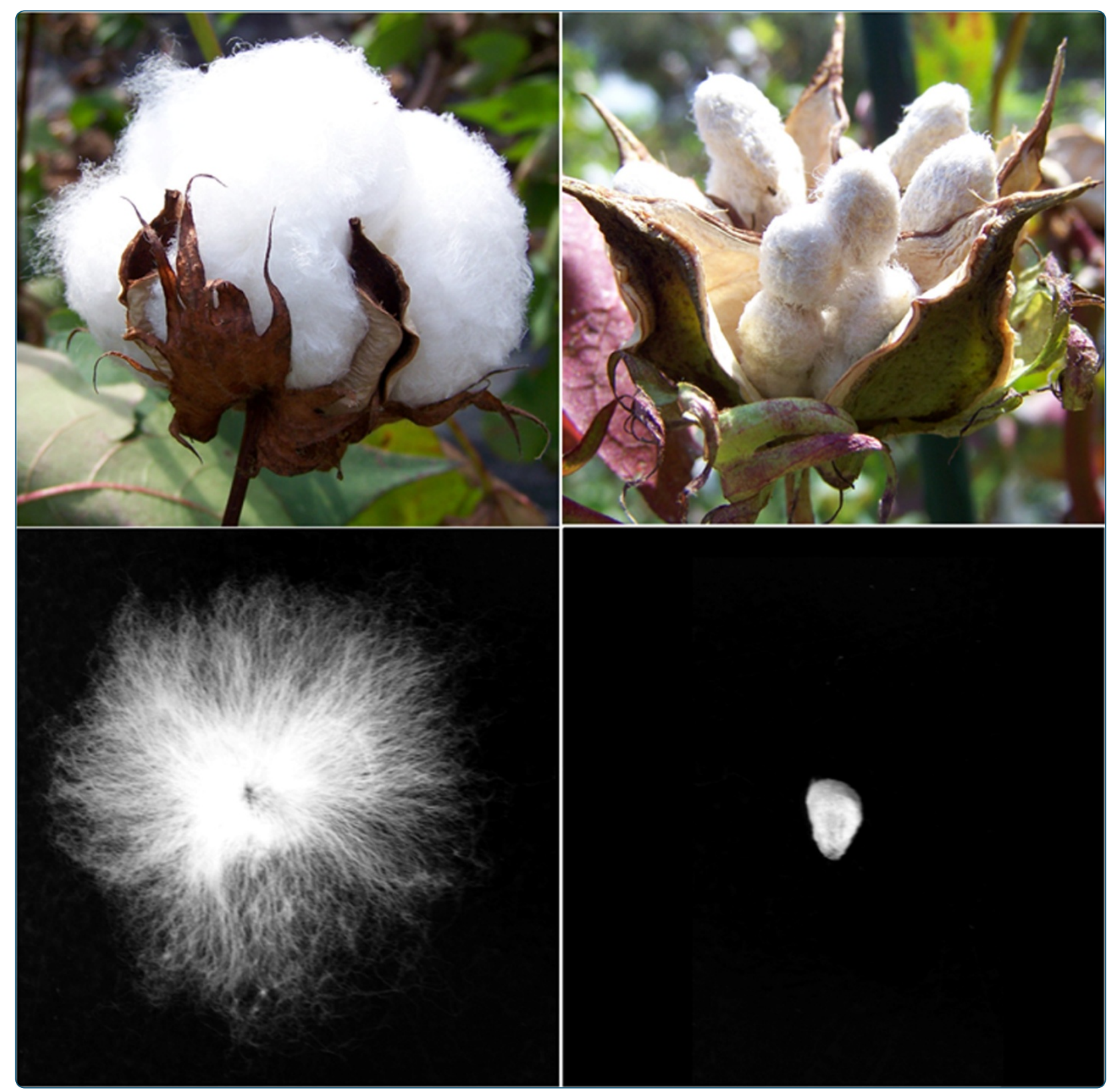

Transcript profiling by microarray and marker analysis of the short cotton (Gossypium hirsutum L.) fiber mutant Ligon lintless-1 $\left(L i_{1}\right)$

Gilbert et al. 


\title{
Transcript profiling by microarray and marker analysis of the short cotton (Gossypium hirsutum L.) fiber mutant Ligon lintless-1 $\left(L i_{1}\right)$
}

Matthew K Gilbert ${ }^{1}$, Rickie B Turley ${ }^{2}$, Hee Jin Kim', Ping Li ${ }^{1}$, Gregory Thyssen ${ }^{1}$, Yuhong Tang ${ }^{3}$, Christopher D Delhom ${ }^{4}$, Marina Naoumkina ${ }^{1}$ and David D Fang ${ }^{1 *}$

\begin{abstract}
Background: Cotton fiber length is very important to the quality of textiles. Understanding the genetics and physiology of cotton fiber elongation can provide valuable tools to the cotton industry by targeting genes or other molecules responsible for fiber elongation. Ligon Lintless-1 $\left(L i_{1}\right)$ is a monogenic mutant in Upland cotton (Gossypium hirsutum) which exhibits an early cessation of fiber elongation resulting in very short fibers $(<6 \mathrm{~mm})$ at maturity. This presents an excellent model system for studying the underlying molecular and cellular processes involved with cotton fiber elongation. Previous reports have characterized $L i$, at early cell wall elongation and during later secondary cell wall synthesis, however there has been very limited analysis of the transition period between these developmental time points.
\end{abstract}

Results: Physical and morphological measurements of the $L i_{1}$ mutant fibers were conducted, including measurement of the cellulose content during development. Affymetrix microarrays were used to analyze transcript profiles at the critical developmental time points of 3 days post anthesis (DPA), the late elongation stage of 12 DPA and the early secondary cell wall synthesis stage of 16 DPA. The results indicated severe disruption to key hormonal and other pathways related to fiber development, especially pertaining to the transition stage from elongation to secondary cell wall synthesis. Gene Ontology enrichment analysis identified several key pathways at the transition stage that exhibited altered regulation. Genes involved in ethylene biosynthesis and primary cell wall rearrangement were affected, and a primary cell wall-related cellulose synthase was transcriptionally repressed. Linkage mapping using a population of 2,553 $\mathrm{F}_{2}$ individuals identified SSR markers associated with the $L i_{1}$ genetic locus on chromosome 22. Linkage mapping in combination with utilizing the diploid G. raimondii genome sequences permitted additional analysis of the region containing the $L i$, gene.

Conclusions: The early termination of fiber elongation in the $L i_{1}$ mutant is likely controlled by an early upstream regulatory factor resulting in the altered regulation of hundreds of downstream genes. Several elongation-related genes that exhibited altered expression profiles in the $L i_{1}$ mutant were identified. Molecular markers closely associated with the $L i_{1}$ locus were developed. Results presented here will lay the foundation for further investigation of the genetic and molecular mechanisms of fiber elongation.

Keywords: Cotton, Ligon Lintless-1, Microarray, Cotton fiber elongation, Microsatellite markers

\footnotetext{
* Correspondence: david.fang@ars.usda.gov

${ }^{1}$ Cotton Fiber Bioscience Research Unit, USDA-ARS, Southern Regional

Research Center, New Orleans, LA 70124, USA

Full list of author information is available at the end of the article
} 


\section{Background}

Cotton seed fibers are single-celled trichomes that initiate from the ovule epidermal cells on or about the day of anthesis (DOA) [1]. Approximately $25 \%$ of the ovule epidermal cells differentiate into fiber cells during the initiation stage of cotton fiber development and subsequently undergo a period of rapid elongation known as the elongation stage $[2,3]$. The rate of fiber elongation peaks at approximately 6 to 12 days post-anthesis (DPA) and nears cessation around 22 DPA [4]. During peak elongation fiber cells can increase in length at rates of 2 $\mathrm{mm} /$ day or more depending on environmental factors and genotypes [5-7]. Beginning at 12-16 DPA and overlapping with the elongation phase is the secondary cell wall (SCW) biosynthesis stage. During this stage cellulose is synthesized and deposited between the primary cell wall and the plasmalemma $[8,9]$. The period of overlap between the elongation stage and the initial stage of SCW biosynthesis is referred as the transition period. Elongation and SCW biosynthesis continue until the fibers reach full length [25-30 mm in Upland cotton (Gossypium hirsutum L.) cultivars] [10], after which the cotton bolls open and the fibers desiccate under exposure to the environment. The environmental and genetic factors that influence the timing of these processes have been shown to also influence the development of desirable fiber traits such as lint yield and fiber quality [7,11-13].

Several naturally occurred cotton mutations affecting a range of fiber phenotypes have been genetically and functionally characterized in cotton. Examples include the completely glabrous seeds (lintless and fiberless) observed in MD17 [14], the fuzzless/lintless $(f l)$ mutant of XZ-142 [15,16], and lines with seeds containing only lint and no fuzz, such as the naked seed lines $N_{1}$ and $n_{2}$ [17]. Mutant lines exhibiting very short seed fibers include the Ligon Lintless- 1 and -2 lines ( $L i_{1}$ and $L i_{2}$ ) $[18,19]$. Recently, Cai et al. [20] analyzed a man-made mutant Lix that showed similar phenotype to $L i_{1}$. The understanding that initiation, elongation, and secondary cell wall synthesis are distinct developmental processes often leads to the utilization of the applicable mutant to study the specific process of interest. For example, $f l$ mutant seeds lacking any fiber emergence have served as models for studying initiation processes where enrichment of the homeodomain-leucine zipper transcription factor (GhHD1) and GhMyb25 were identified as important for initiation [21,22]. Likewise, $N_{1}$, with its lack of fuzz fiber and sparsely-distributed lint fibers has been used to characterize fiber elongation processes [17].

In a near-isogenic state with the cotton line Texas Marker-1 (TM-1), both the $L i_{1}$ and $L i_{2}$ mutants have seed fibers that are extremely short $(<6 \mathrm{~mm})$ compared to wild type (WT) fibers that are typically greater than
$20 \mathrm{~mm}$ in length $[19,23,24]$. As a monogenic dominant trait, the short-fiber phenotypes of $L i_{1}$ and $L i_{2}$ are identical in either a homozygous dominant or heterozygous state. Unlike the $L i_{2}$ mutant which appears healthy and morphologically identical to the homozygous recessive wild-type plants with the exception of shorter seed fibers, the $L i_{1}$ mutant exhibits pleiotropy in the form of severely stunted and deformed plants in both the homozygous dominant and heterozygous state [23].

Since the seed fibers of $L i_{1}$ and $L i_{2}$ fibers are shortened lint and fuzz fibers, these cotton mutants represent excellent candidates to study the molecular mechanisms of fiber elongation. Previously, our laboratory conducted extensive analysis of the $L i_{2}$ mutant using microarray technology, molecular mapping and metabolomic analysis $[25,26]$. We developed microsatellite markers associated with the $L i_{2}$ genetic locus, and identified transcripts or genes and metabolites that were affected by the $\mathrm{Li}_{2}$ mutation. In order to gain more comprehensive knowledge about cotton fiber development, and especially fiber elongation, we included the $L i_{1}$ mutant as a subject of our investigation.

The $L i_{1}$ mutant has been used as a model to study both primary and secondary cell wall processes [27-30]. However, previous microarray experiments with the $L i_{1}$ mutant conducted during either very early elongation or later SCW stage failed to identify significant numbers of differentially expressed transcripts. For example, the microarray experiments conducted by Bolten et al.[28] using 24 DPA fibers only identified $\sim 100$ differentially expressed transcripts, notable among them SuSy, Expansins, and $M y b$ transcription factors. However, apparent phenotypic differences in the $L i_{1}$ as early as 3 DPA [31] indicating that altered gene expression may exist at or before this stage. Noting this, a microarray experiment conducted by Liu et al. [27] analyzed the $L i_{1}$ mutant at the initiation and elongation stages of 0,3 and 6 DPA. Their findings concurred with several earlier studies on the relevance of auxin, gibberellins, brassinosteroid and ethylene-related pathways in fiber development. Elongation stage (6 DPA) fibers from $L i_{1}$ demonstrated a significant alteration in transcript profiles, with 1,398 target sequences showing altered expression in the mutant. Despite this, a crucial gap remains in our understanding of how the $L i_{1}$ mutation affects the transcript profile at the transition period (later elongation stages and early SCW stages). This paper is the first attempt to analyze gene expression patterns in the $L i_{1}$ mutant using microarray technology at these critical developmental stages. Here we provide a more complete picture of the molecular events directly controlling fiber elongation. Further, it will better define the mutation in terms of its effects on primary cell wall elongation and early secondary cell wall synthesis. 
Prior research has determined that the $L i_{1}$ gene is located on chromosome 22 using both SSR [31] and RFLP markers [32]. Karaca et al. [31] identified the SSR marker MP4030 that was $12.83 \mathrm{cM}$ away from the $L i_{1}$ locus. Rong et al. [32] provided the highest resolution to date, determining $L i_{1}$ was flanked by RFLP markers Gate4CA09 and Coau1J04 at 2.7 and $1.3 \mathrm{cM}$ away, respectively, based on $151 \mathrm{~F}_{2}$ progeny derived from an interspecific cross of $G$. barbadense Pima S-7 $\times L i_{1}$ mutant.

In order to conduct a comprehensive study of the $L i_{1}$ mutant, we first created near-isogenic lines (NIL) in DP5690 genetic background by implementing an extensive backcross scheme. The use of DP5690, a modern variety, exhibits stronger growth characteristics than TM-1 in many climates and permits for additional analysis with the previously characterized Ligon Lintless-2 $\left(L i_{2}\right)$, which is also in the DP5690 background [25]. Using the two NILs as parents, we made a very large $F_{2}$ population comprising 2,553 progeny which was used to identify molecular markers closely associated with the $L i_{1}$ locus. To understand the molecular events that control fiber elongation and identify regulatory elements involved in this process, we obtained transcript profiles at 3 DPA (beginning of elongation), 12 DPA (late elongation stage) and 16 DPA (early SCW) using Affymetrix microarrays, and analyzed morphological characteristics of fibers from the $L i_{1}$ NILs at different developmental stages. The objectives of this research were to determine the location of the $L i_{1}$ locus on the chromosome, and identify genes that were differentially expressed during the development of WT and mutant $L i_{1}$ fibers. This information will, in turn, be useful to identify the $L i_{1}$ gene, and help to elucidate the molecular mechanisms of this gene on fiber elongation.

\section{Methods \\ Plant materials for microarray and quantitative PCR (qPCR) experiments}

Two near-isogenic lines of $L i_{1}$ Upland cottons (Gossypium hirsutum L.) that were homozygous dominant $\left(L i_{1} L i_{1}\right)$ and homozygous recessive $\left(l i_{1} l i_{1}\right)$ for the $L i_{1}$ locus were developed in a backcross program at Stoneville, MS in field and greenhouse environments (Figure 1A). Texas marker-1 (TM-1) cotton plants containing the $L i_{1}$ gene were crossed with the Upland cotton variety DP5690. $\mathrm{F}_{1}$ progeny were backcrossed for five generations $\left(\mathrm{BC}_{5}\right)$ by single seed decent (SSD) to DP5690 which served as the recurrent parent in each backcross. At the end of $\mathrm{BC}_{5}$ cycle, plants with $L i_{1}$ phenotype were self-pollinated. The DP5690 recurrent parent was a pure inbred line that was self-pollinated for nine generations via SSD (Additional file 1). Progenies in each backcross were selected based on the phenotype for the $L i_{1}$ short-fiber mutation.
For the microarray and qPCR experiments, a total of 100 homozygous $\left(L i_{1} L i_{1}\right) L i_{1}$ mutant and $100 \mathrm{WT}\left(l i_{1} l i_{1}\right)$ plants were planted in a field at the Southern Regional Research Center, New Orleans, LA in the summers of 2011 and 2012. The soil type in New Orleans was Aquent dredged over alluvium in an elevated location to provide adequate drainage. Flowers were tagged and sample collections were made before 10:00 am and immediately placed on ice. All samples collected within each developmental stage were tagged and collected on the same day. Fruits were randomly grouped into 3 individual replicates with 5-10 fruits per replicate. Fruits were then dissected, frozen in liquid nitrogen and stored at $-80^{\circ} \mathrm{C}$ until further processing.

\section{Mapping population}

A WT DP5690 $\left(l i_{1} l i_{1}\right)$ was used as the female in a cross with its near-isogenic mutant line $\left(L i_{1} L i_{1}\right.$ homozygous plant). Two thousand five hundred fifty-three $F_{2}$ plants derived from approximately $20 \mathrm{~F}_{1}$ plants were planted along with their parents in a field in Stoneville, MS in 2012. The $L i_{1}$ trait of each $F_{2}$ progeny plant was evaluated after boll maturation and opening (about 60 DPA). Standard conventional field practices were applied during the growing season. The soil type in Stoneville, MS was Bosket very fine sandy loam.

\section{Fiber length and cellulose content measurements}

Fiber length was measured using the method described by Schubert et al. [6]. Two replicate samples with 10 ovules each were measured. For mass determination, airdried fibers were gently removed from all ovules of each sample, and weighted on an analytical balance. Cellulose content from each fiber sample was measured using the method described by Updegraff [33] with minor modification. Dried fiber samples were cut into small pieces. Ten $\mathrm{mg}$ of the blended fibers were placed in $5 \mathrm{~mL}$ Reacti-Vials $^{\text {Ts }}$ (Thermo Fisher Scientific, Waltham, MA). Non-cellulosic materials in fibers were hydrolyzed with acetic-nitric reagent. The remaining cellulose was hydrolyzed with sulfuric acid and measured by a colorimetric assay with anthrone using Avicel PH-101 (FMC, Rockland, ME) as a cellulose standard. The average cellulose content for each fiber sample was obtained from two biological and three technical replications.

\section{Imaging analysis of fiber cross-sections}

Fibers from 28 and 40 DPA were manually separated from the seed. After bundling the fibers together, a new razor blade was used to cut $2.5-3 \mathrm{~mm}$ of fiber from the end to be sectioned. This ensured a majority of fibers were cross-sectioned near the middle of the fiber. The fiber samples were embedded, thin-section cut, and photographed using the method previously described 


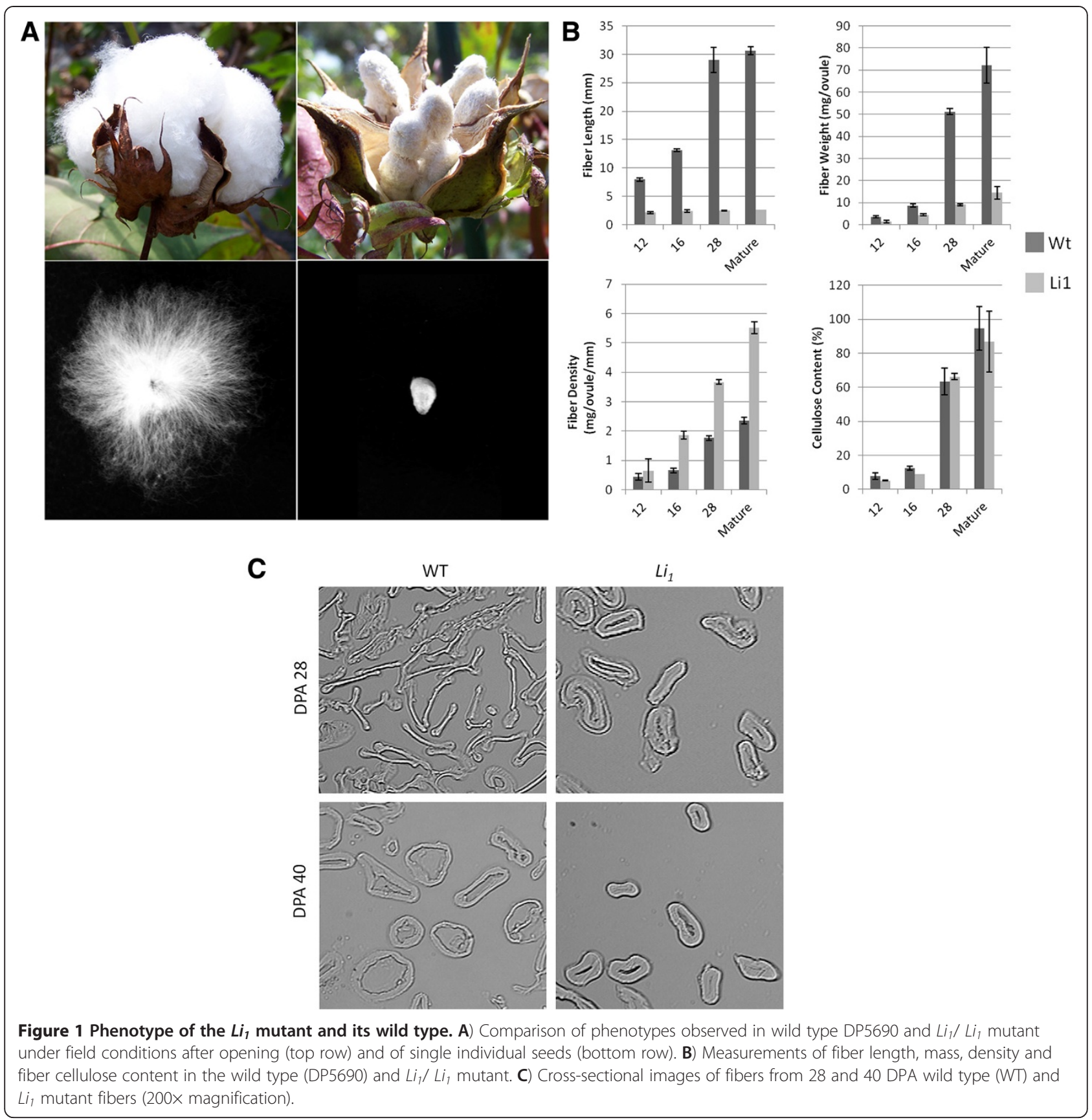

[34]. The images were taken using a Nikon Cambridge Quantimet 900 microscope at 200× magnification with a Hitachi KP-DSO camera.

\section{RNA isolation from cotton fibers}

RNA was isolated as previously described [25]. Briefly, material was obtained from developing ovules using a glass bead shearing technique [35]. To separate the fibers from the ovules the samples were shaken vigorously enough to break fibers without damaging the ovules. Isolation of RNA was conducted using the Sigma Spectrum ${ }^{\mathrm{Tm}}$ Plant Total RNA Kit (Sigma-Aldrich, St. Louis, MO) with on-column DNaseI digestion according to the manufacturer's instructions. RNA quantity was determined by using a Nanodrop 2000 spectrophotometer (NanoDrop Technologies Inc., Wilmington, DE). A RNA integrity number (RIN) was determined for each sample using an Agilent Bioanalyzer 2100 and the RNA 6000 Nano Kit Chip (Agilent Technologies Inc., Santa Clara, CA). Only samples with RIN values of 7.0 or higher were used for further analysis. 


\section{Microarray hybridizations and data analysis}

The minimum information about microarray experiments (MIAME) guidelines were followed for all microarray experiments conducted in this study [36]. The microarray chips used for this study were the commercially available Affymetrix GeneChip ${ }^{\circledR}$ Cotton Genome Microarray (Affymetrix Inc., Santa Clara, CA), comprising 239,777 probe sets representing 21,854 cotton transcripts from a variety of EST databases. Labeling of the RNA was conducted using the Affymetrix GeneChip ${ }^{\circledR}$ 3' IVT Express Kit and hybridizations were conducted according to the manufacturer's protocols. Hybridizations were conducted on 3, 12, and 16 DPA samples with two biological replicates from each developmental stage. Data normalization and the determination of statistically relevant deviations in expression patterns were performed as described [37]. To assist in analysis of biological processes represented in the data, Gene-Ontology Enrichment Analysis (GOEA) was performed using the agriGO Singular Enrichment Analysis tool [38]. The statistical test method used was the Fisher's Exact test (significance level 0.05). Annotation of the probe sets was accomplished with Blast2Go [39], and analysis of the cellulose synthase probes was conducted by translating all 6 reading frames of the probe sets and subjecting them to blastp analysis.

To investigate the activity of known cell elongation and cell wall-related genes, the microarray probe sets were compared with published lists of genes $[27,40]$. Each probe set reference sequence was aligned to the G. raimondii reference genome [41] with blastn and the best hit with e value of $1 \times 10^{-30}$ or smaller was used to establish an annotation. The G. raimondii gene annotations specify an arabidopsis homolog for each gene, which was used to classify the functions of each Affymetrix probe set. Seventy-four probe sets were classified as elongation genes based on an earlier report [27]. To classify probe sets as primary or secondary cell wall genes, co-expression with arabidopsis microarray data with known primary or secondary cell wall cellulose synthase genes [40] was obtained from ATTEDII [42]. This strategy produced lists of 81 primary cell wall and 43 secondary cell wall gene probe sets.

\section{Reverse transcription and quantitative PCR}

The cDNA reactions were performed using the iScript ${ }^{\mathrm{m}}$ cDNA Synthesis kit (Bio-Rad Laboratories, Hercules, CA) per the manufacturer's instructions. The reaction without reverse transcriptase served as negative control for testing genomic DNA contamination of the RNA samples. This reaction was then used as template in a qPCR reaction to verify that no amplification occurred. After cDNA synthesis, the qPCR reaction was conducted using iTaq ${ }^{\mathrm{TM}} \mathrm{SYBR}^{\circledR}$ Green Supermix (Bio-Rad Laboratories) in a Bio-Rad CFX96 real time PCR detection system. PCR conditions and the protocols for determining primer efficiencies were as previously described [25]. Ubiquitin-conjugated protein (UCP) (Genebank AI730710) was used as the endogenous reference gene. Primer sequences are listed in Additional file 2 .

\section{SSR marker analysis and genetic mapping}

Young leaves were collected from each individual $\mathrm{F}_{2}$ plant and parents, and stored at $-80^{\circ} \mathrm{C}$. Total DNA was extracted from frozen leaves according to Fang et al. [43]. The $L i_{1}$ gene was previously determined to reside on chromosome 22 (Chr. 22) [31,32]. To rapidly identify molecular markers closely linked to the $L i_{1}$ locus, all simple sequence repeat (SSR) markers that were mapped on both Chr.22 and its homeologous Chr. 4 based on the high density consensus genetic map [44] were selected for analysis. RFLP markers reported by Rong et al. [32] were not screened due to unavailability of probes, and technical difficulties for RFLP marker analysis. The SSR markers mapped on Chr. 5 and its homeologous Chr.19 were also included because of a known translocation between Chr. 4 and Chr. $5[45,46]$. All together, a total of 921 SSR markers mapped in these four chromosomes were screened for polymorphism between DNA bulks. For the WT bulk, DNA of $10 \mathrm{~F}_{2}$ plants with WT phenotype were pooled at equal ratio and diluted to $50 \mathrm{ng} / \mu \mathrm{L}$. The mutant type bulk consisted of DNA from $10 \mathrm{~F}_{2}$ plants with short seed fiber. Four DNA bulks were made, two for each type. The polymorphic markers were then analyzed using $96 \mathrm{~F}_{2}$ progeny to identify markers closely associated with the $L i_{1}$ locus. Only SSR markers that revealed less than 10 recombination events were analyzed among the total $2,553 \mathrm{~F}_{2}$ progeny plants.

The PCR amplification conditions and marker data acquisition were according to Fang et al. [43]. All SSR primer sequences can be obtained from Cotton Marker database (www.cottonmarker.org). Segregation data for the $L i_{1}$ trait and SSR markers were mapped using program JoinMap4.0 [47] with logarithm of odds score $=25$.

\section{Functional analysis of the $L i_{1}$ region}

To obtain sequences in the region determined to contain the $L i_{1}$ mutant gene, the identified SSR marker sequences were aligned to the diploid $G$. raimondii $\mathrm{D}_{5}$ genome [41]. We also blasted other SSR marker sequences from the $L i_{1}$ interval of Chr. 22 based on the high density consensus map [44]. This permitted comparison of the gene annotations for this interval with the annotations provided by Affymetrix to identify candidate genes. qPCR on select genes was conducted as described above.

\section{Sequencing introns to develop additional polymorphic markers}

To identify additional polymorphisms that could facilitate finer mapping of the $L i_{1}$ locus, we sequenced introns from 
the annotated genes in the $17 \mathrm{Mb}$ interval between the markers TMB2500 and DPL0489 according to the reference G. raimondii genome sequences. Our rational to sequence introns was that introns tend to have higher sequence variations than exons. We designed primers that flanked 23 introns but were anchored in protein coding sequences. Three genes that resided in this interval and showed differential expression between WT and mutant were included. Amplicons were generated from total genomic DNAs of the parental lines and two $F_{2}$ individuals (one WT type and one mutant type) and were Sanger sequenced.

\section{Results}

\section{Fiber structure analysis}

Early literature indicated that the $L i_{1}$ mutant in a TM-1 genetic background demonstrated a reduced rate of crystalline cellulose deposition during primary cell wall synthesis and an increased rate during SCW synthesis, resulting in a "thickened" appearance of the cell wall in the mutant $[18,30]$. However, it remains unclear if this effect is due primarily to the mutation causing inhibition of fiber elongation processes or due to the mutation affecting SCW synthesis processes such as cellulose deposition, or both. To better characterize phenotypic changes in the mutant during late elongation and secondary cell wall deposition, changes in fiber length, mass, density, and cellulose content over developmental times were measured. Grown in standard field conditions in New Orleans, LA, the homozygous $L i_{1}$ mutant demonstrated a characteristic short fiber phenotype and other previously characterized pleiotropic characteristics (Figure 1A and Additional file 3). Heterozygous individuals derived from DP5690 x $L i_{1} L i_{1}$ crosses demonstrated a dosage effect resulting in an intermediate plant size (Additional file 3). Measurements of fiber physical properties indicated that $L i_{1}$ mutants had a dramatic difference in both length and fiber dry weight (mg/seed) at the developmental stages measured (Figure 1B) as compared to the WT. Elongation ceased or remained static in the $L i_{1} \mathrm{mu}-$ tant by $12 \mathrm{DPA}$, however fiber dry weight continued to increase during SCW synthesis and through to maturity, likely due to the continued deposition of cellulose. Calculating fiber density further illustrated the continued increase in biomass observed over the developmental stages and a much higher density in comparison to the WT. However, the overall cellulose content per unit mass was similar between WT and the $L i_{1}$ mutant in 12, 16, 28 DPA and mature fibers. Image analysis indicated the $L i_{1}$ mutant fibers at $28 \mathrm{DPA}$, (the youngest stage that was technically obtainable), were in general "thicker" than WT fibers (Figure 1C), which corroborated our observations on the increasing mass of the fibers. Combined, these results suggested that while thickening of the secondary cell wall occurred through developmental stages, it was not due to a relative increase in overall cellulose content or rate of production per fiber cell in the $L i_{1}$ mutant. Rather, due to early cessation of fiber elongation, the stunted fiber did not distribute the cellulose along its longitudinal axis, thus resulting in a thickened appearance, and an increased mass per unit length.

\section{Microarray analysis}

All three developmental time points analyzed demonstrated alterations in gene expression in the $L i_{1}$ mutant. At 3 DPA the effects of the mutation were relatively limited, showing only a total of 223 genes up-regulated and 191 genes down-regulated ( $\geq 2$-fold change; < Bonferronicorrected p-value threshold 2.07194E-06). Of importance, 250 of these probe sets were unique to $3 \mathrm{DPA}$ and were not differentially expressed at 12 or 16 DPA (Figure 2A). At 12 DPA and 16 DPA, 1,384 and 1,435 genes were differentially expressed, respectively. To analyze which developmental processes were affected in the $L i_{1}$ mutant, target sequences previously identified as elongation, primary cell wall synthesis, or secondary cell wall synthesis were tabulated in each of the experimental categories. Figure 2B illustrates that more than a quarter of primary cell wall genes were down-regulated in the $L i_{1}$ mutant at 12 DPA, as were a third of secondary cell wall biosynthesis genes at 16 DPA. Very few cell wall-related probe sets were up or down-regulated at 3 DPA (Additional file 4). This analysis revealed that while the $L i_{1}$ mutation affected transcriptional activity at all stages of development, a major effect was the inhibition of primary cell wall-related factors in addition to a limited effect on secondary cell wall-related processes.

Gene Ontology Enrichment Analysis (GOEA) [38] of differentially expressed genes at 3 DPA indicated that no significant enrichment pertaining to a biological or molecular processes occurred at this stage in the $L i_{1}$. GOEA analysis indicated that a large number of genes involved in known biological processes were detectable at 12 DPA, and many of these categories are known to be elongationrelated processes, eg, xyloglucan endotransglucosylase [48], beta-galactosidase [49], shaggy-related kinase (bin2) [50], and auxin response genes [51] (Table 1). Importantly, there was essentially no enrichment of probes specific for any biological or molecular processes that showed altered regulation at 16 DPA only.

A significant number of processes that were common to $12 \mathrm{DPA}$ and $16 \mathrm{DPA}$, but not to 3 DPA showed altered expression in the mutant (Additional file 5). GOEA analysis of this category of genes indicated a large decrease in probe sets categorized in nucleosome assembly (GO:0006334) and lipid transport (GO:0006869). There was an increase in mitochondrial electron transport (GO:0006120), which includes NADH-dehydrogenase genes and NADH- 

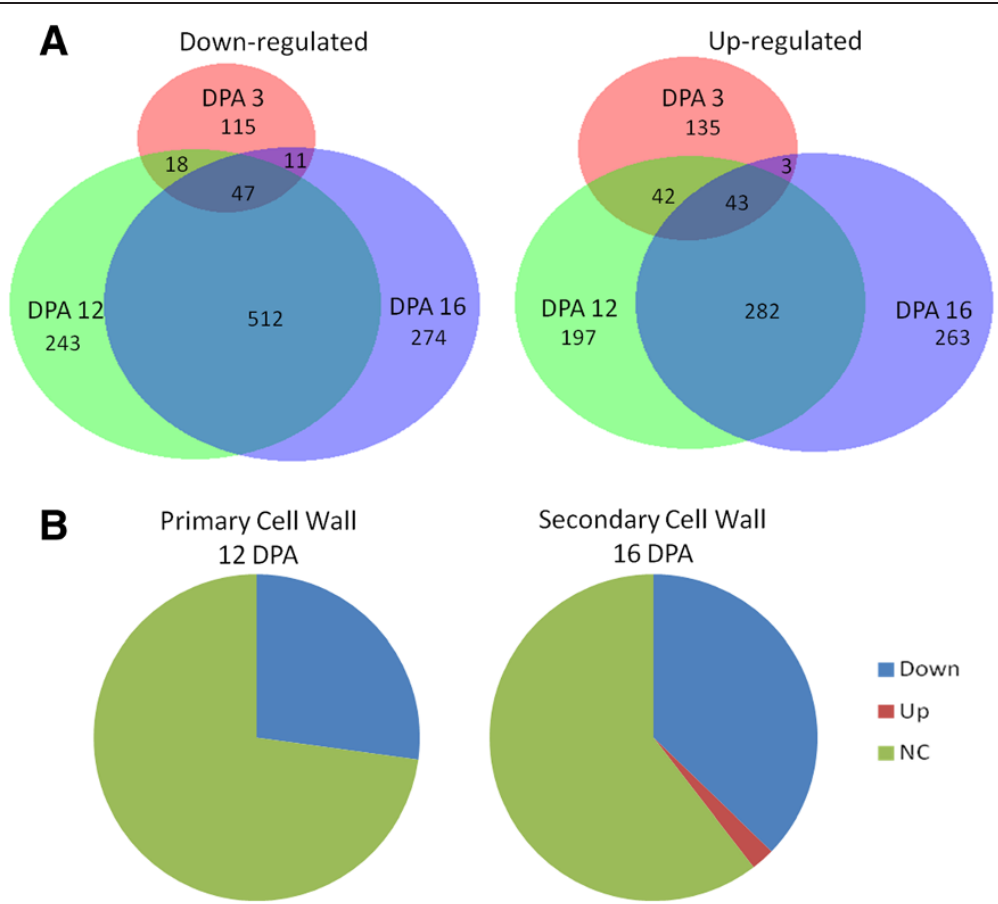

Figure 2 Results of the microarray analysis comparing $L i_{1}$ and its WT NIL in DP5690 background. A) The distribution and number of probe sets from the microarray showing altered regulated by $>2$ fold in $L i_{1}$. B) Pie diagram illustrating the relative percentages of probe sets showing altered regulation in the $L i$, mutant that were identified as primary cell wall related in 12 DPA fiber samples and secondary cell wall related in 16 DPA fibers.

plastoquinon oxidoreductase subunits, both members of Complex I of the electron transport chain, known to be high producers of reactive oxygen species (ROS) [52].

Fiber development-related genes show altered expression patterns in the $L i_{1}$ fibers (Table 2, more comprehensive list in Additional file 6). A large number of auxin, ethylene, and gibberellins responsive transcription factors were differentially expressed, as were cytoskeleton components such as tubulin and profilin. Five probe sets identifying 1-Aminocyclopropane-1-Carboxylic Acid Oxidase genes, responsible for ethylene biosynthesis, were differentially expressed. Ghi.798.1, identified as GhACO3, demonstrated significant up-regulation in the mutant, as did an uncharacterized ACO homologue (GhiAffx.16665). However, GhACO4 (Ghi.8025) and another uncharacterized $A C O$ homologue (Ghi.6502) were down-regulated in the mutant, suggesting divergent roles in fiber elongation processes. Another key enzyme in ethylene biosynthesis, 1Aminocyclopropane-1-carboxylate synthase $(A C C)$ [53,54], was down-regulated in the mutant at 12 DPA. Ghi.5451 shares 100\% homology with ACC Synthase 3 and 6 (GhACS 3/6) (Table 2).

Twelve probe sets representing an unknown number of $\mathrm{AP2} / \mathrm{ERF}$ (ethylene response factor) domain-containing transcription factors were significantly differentially expressed, with the majority demonstrating down-regulation (e.g. Ghi.7874) (Table 2 and Additional file 6). Eight probe sets measuring levels of the pathogenesis-related 10 (PR10) proteins, a family of defense and stress-related genes regulated by jasmonic acid, ethylene and other effectors [71] exhibited expression patterns 8 to 96 fold higher in the $L i_{1}$ mutant. Sucrose Synthase 1 (Sus1) was highly up-regulated (56-fold) at 3 DPA in the $L i_{1}$ mutant, then not differentially expressed at 12 DPA and 16 DPA.

\section{Transcription analysis of cellulose synthase activity}

Cellulose synthases and cell wall re-arranging proteins have been a subject of interest as they relate to fiber elongation. More specifically, defining the role of specific cellulose syntheses in so far as their specificity for either primary or secondary cell wall processes is relevant to understanding elongation. Previous research has speculated, and some data has suggested, that altered cellulose deposition determined the $L i_{1}$ phenotype [18,30]. In light of this, it was of value to further analyze cellulose synthase expression levels in the $L i_{1}$ mutant. Probe sets annotated as cellulose synthase $(\mathrm{Ces})$ genes or cellulose synthase-like $(C s l)$ were identified by Blast2Go annotation, Affymetrixprovided annotation terms, and by blastx analysis of the microarray probe sets. Quantitative PCR analysis was conducted on selected Ces genes. Of the 38 probe sets annotated as Ces or Csl, only 1 probe set, GhiAffx.58712 demonstrated reproducible $>2$ fold altered gene expression in the $L i_{1}$ mutant at the developmental stages analyzed 


\begin{tabular}{l} 
Table 1 Gene ontology analysis results of target sequences that are up or down regulated in the $\mathrm{Li}_{1}$ mutant at 12 DPA \\
or 16 DPA \\
$\begin{array}{lll}\text { Category } & \begin{array}{l}\text { Gene ontology } \\
\text { categorization* }\end{array} & \text { Representative annotations of probed sequences (Li1/Wt expression ratio) }\end{array}$ \\
\hline
\end{tabular}

Unique to 12 Response to hormone stimulus GO:0009725 (0.00023) DPA

eg. indole-3-acetic acid-amido synthetase (0.48), xyloglucan endotransglucosylase (2.2), shaggy-related kinase (2.1), auxin-responsive protein (.34) and auxin response (0.42).

Response to cytokinin stimulus GO:0009735 (0.00014)

eg. ap2 erf domain-containing transcription factor (2.1), homeobox protein knotted-1-like 3-like (2.1)

Transmembrane receptor protein tyr kinase signaling pathway GO:0007169 (1.9e-06)

e.g. strubbelig-receptor family 7 protein (0.45), Irr receptor-like serine threonine-protein kinase (0.35),

Protein amino acid phosphorylation GO:0006468 (1.5e-05)

e.g. cyclin-dependent kinase $\mathrm{f}-4$-like $(0.48)$, shaggy-related protein kinase eta-like (2.07), serine threonineprotein kinase aurora-1 (.43), feronia receptor-like kinase (0.43)

Hydrolase activity, hydrolyzing O-glycosyl compounds GO:0004553 (3e-07)

e.g. cobra-like 4 protein (3.74), beta galactosidase 1 (0.46), xyloglucan endotransglucosylase hydrolase (0.44), acidic chitinase (3.32), xyloglucan endotransglucosylase hydrolase protein 2 (2.33), beta-xylosidase alpha-I -arabinofuranosidase 2-like $(0.43)$

Xyloglucan:xyloglucosyl transferase activity GO:0016762 (0.00016)

e.g. xyloglucan endotransglucosylase hydrolase (0.41), xyloglucan endotransglucosylase hydrolase protein 2

(2.33), probable xyloglucan endotransglucosylase hydrolase protein 32-like (2.56)

Protein kinase activity GO:0004672 (0.00075)

serine threonine-protein kinase (3.12), probable receptor-like serine threonine-protein kinase at5g57670-like (11.02)

Unique to 16 Cellular nitrogen compound metabolic process GO:0034641 (1.1e-05)

DPA

glutamine synthetase (2.05), phenylalanine ammonia-lyase (0.26), asparagine synthetase (2.06), serine threonine protein kinase 2 (3.23)

*e-value in parenthesis.

(Figure 3). Probe set GhiAffx.58712 sequence was derived from one of 28 EST's homologous to sequence accession [GenBank:GQ200733]. In the WT the target sequence expression levels were relatively high at 8 DPA and 12 DPA, then decreased at 16 DPA indicating potential function as a primary cell wall-related Ces (Figure 3F). Importantly, the $L i_{1}$ mutant showed decreased expression levels relative to WT at the elongation stages analyzed. GhiAffx.58712.1 was identified as GhCesA6 [GenBank:ACS88358], which shares $86 \%$ protein sequence identity with $A$. thaliana CesA6 [GenBank:NP_201279], which is known to be important in primary cell wall synthesis [72]. Other sequences analyzed; Ghi.1151 (GhCesA1), Ghi.6061 (GhCesA2), Ghi.5191 (GhCesA3), Ghi.8518 (GhCesA5) and Ghi.3562.1 (Cellulose synthase-like E1, CSLE1) did not demonstrate altered expression in the $L i_{1}$ mutant (Table 2 and Figure 3A-E).

\section{Corroboration of microarray data}

Sequences targeted by the microarray were selected for quantitative PCR analysis to corroborate the results obtained in the microarray (Table 3). The selected sequences included genes that were up-regulated, down- regulated, and demonstrated no change in the $L i_{1}$ mutant. The 24 samples analyzed ( 8 probe sets, 3 developmental stages) by qPCR demonstrated results consistent with the microarray analysis. The probe sets targeting cellulose synthase-like protein e6-like demonstrated little alteration in gene expression in the $L i_{1}$ mutant according to the microarray data, and similar results were obtained with qPCR analysis. One of the eight probe sets targeting pathogenesis-related protein 10 family (Ghi.6485) exhibited a dramatic increase in expression, showing 127 fold and 191 fold increase in 12 DPA and 16 DPA, respectively. Expansin a10, a cell wall structural protein, was down-regulated at 12 and 16 DPA in microarray and qPCR, as were most expansins (Additional file 6). Expansin-like b1 was the only expansin up-regulated at 12 DPA, however the qPCR data for this gene was not entirely consistent with microarray data for 16 DPA. Betagalactosidase, which hydrolyses $\beta$-glycosidic bonds and is thought to be important for primary cell wall rearrangement, was down-regulated as measured by qPCR and microarray in all stages of development in the mutant. TubulinA4 was expressed at extremely high levels (data 
Table 2 Select elongation-related probe sets showing altered regulation in the $\mathbf{L i}_{\mathbf{1}}$ mutant*

\begin{tabular}{|c|c|c|c|c|c|c|}
\hline \multicolumn{7}{|c|}{ Genes up-regulated in the $L i_{1}$ mutant relative to its near isogenic wild type line } \\
\hline Probe ID & Annotation & 3DPA & 12DPA & 16DPA & Heterologous functions & Ref. \\
\hline $\begin{array}{l}\text { Ghi.798.1. } \\
\text { S1_S_at }\end{array}$ & $\begin{array}{l}\text { 1-aminocyclopropane-1- } \\
\text { carboxylate oxidase }\end{array}$ & $\underline{2.45}$ & $\underline{10.95}$ & $\underline{5.08}$ & GhACO3, ethylene biosynthesis, elongation related & {$[55]$} \\
\hline $\begin{array}{l}\text { GhiAffx.16665.1. } \\
\text { S1_s_at }\end{array}$ & $\begin{array}{l}\text { 1-aminocyclopropane-1- } \\
\text { carboxylate oxidase } \\
\text { homolog 4-like }\end{array}$ & 1.48 & $\underline{2.87}$ & $\underline{2.54}$ & no homology known & \\
\hline $\begin{array}{l}\text { Ghi.8264.1. } \\
\text { S1_S_at }\end{array}$ & $\begin{array}{l}\text { brassinosteroid-regulated } \\
\text { protein bru1 }\end{array}$ & 0.81 & $\underline{4.11}$ & $\underline{6.99}$ & $\begin{array}{l}\text { homology to xyloglucan endotransglcosylase (AT4G14130.1), } \\
\text { expression correlates with elongation inhibition }\end{array}$ & {$[56]$} \\
\hline $\begin{array}{l}\text { Ghi.5860.1. } \\
\text { S1_S_at }\end{array}$ & $\begin{array}{l}\text { fasciclin-like } \\
\text { arabinogalactan protein }\end{array}$ & 1.10 & $\underline{56.47}$ & $\underline{0.16}$ & $\begin{array}{l}\text { EST from fiber, homology to G. hirs. fasciclin-like arabinogalactan } \\
\text { protein } 3 \text { (FLA3). AtFLA3 overexpression leads to defective } \\
\text { elongation in stamen. }\end{array}$ & {$[57]$} \\
\hline $\begin{array}{l}\text { GhiAffx.36662.1. } \\
\text { S1_s_at }\end{array}$ & r2r3-myb transcription & 1.60 & $\underline{4.25}$ & $\underline{6.40}$ & $\begin{array}{l}\text { At4g37260, MYB73. Highly responsive to ethylene, ABA. } \\
\text { Downregulated in } \mathrm{fl} \text { mutant elonagtion phase. }\end{array}$ & {$[58,59]$} \\
\hline $\begin{array}{l}\text { GhiAffx.60562.1. } \\
\text { S1_at }\end{array}$ & $\begin{array}{l}\text { ethylene-responsive } \\
\text { transcription factor wri1 }\end{array}$ & 0.79 & $\underline{0.31}$ & $\underline{0.26}$ & wri1-1 mutants demonstrate defective elongation of hypocotyl. & [60] \\
\hline $\begin{array}{l}\text { Ghi.2039.2. } \\
\text { S1_s_at }\end{array}$ & sucrose synthase sus1 & $\underline{35.38}$ & 1.60 & 1.38 & $\begin{array}{l}\text { GhSus1 isoform C, targeted to cell wall during secondary cell wall } \\
\text { synthesis. }\end{array}$ & [61] \\
\hline $\begin{array}{l}\text { Ghi.7911.1. } \\
\text { S1_x_at }\end{array}$ & $\begin{array}{l}\text { xyloglucan } \\
\text { endotransglucosylase } \\
\text { hydrolase }\end{array}$ & $\underline{0.42}$ & $\underline{9.24}$ & 8.22 & $\begin{array}{l}\text { TCH4, dwarf A. thaliana mutants have reduced expression, } \\
\text { elongation related. }\end{array}$ & [62] \\
\hline $\begin{array}{l}\text { GhiAffx.10621.1. } \\
\text { A1_s_at }\end{array}$ & $\begin{array}{l}\text { pollen ole e } 1 \text { allergen and } \\
\text { extensin family protein }\end{array}$ & 1.21 & $\underline{32.53}$ & 0.67 & Uncharacterized EST & \\
\hline \multicolumn{7}{|c|}{ Genes down-regulated in the $L i_{1}$ mutant relative to its near isogenic wild type line } \\
\hline $\begin{array}{l}\text { Ghi.8025.1. } \\
\text { S1_S_at }\end{array}$ & $\begin{array}{l}\text { 1-aminocyclopropane-1- } \\
\text { carboxylate oxidase }\end{array}$ & 1.37 & $\underline{0.36}$ & $\underline{0.32}$ & $\begin{array}{l}\text { ACO4, ethylene biosynthesis, induced in ovule culture by fatty acid } \\
\text { synthesis, increasing ethylene production and root elongation. }\end{array}$ & {$[55,63]$} \\
\hline $\begin{array}{l}\text { Ghi.6502.1. } \\
\text { S1_at }\end{array}$ & $\begin{array}{l}\text { 1-aminocyclopropane-1- } \\
\text { carboxylate oxidase }\end{array}$ & 1.13 & 0.63 & $\underline{0.14}$ & $\begin{array}{l}\text { EST, significant homology to ACO proteins, but not identical to } \\
\text { ACO1-4 }\end{array}$ & \\
\hline $\begin{array}{l}\text { Ghi.5451.1. } \\
\text { S1_at }\end{array}$ & $\begin{array}{l}\text { 1-aminocyclopropane-1- } \\
\text { carboxylate synthase }\end{array}$ & 0.78 & $\underline{0.47}$ & 0.88 & Highest homology with GhACS 3/6 & \\
\hline $\begin{array}{l}\text { GhiAffx.12577.1. } \\
\text { S1_at }\end{array}$ & gibberellin 20-oxidase & 0.95 & $\underline{0.34}$ & $\underline{0.15}$ & $\begin{array}{l}\text { gibberellin synthesis, stimulated by Auxin treatment in A. thaliana, } \\
\text { which also causes hypocotyl cell elongation. Increased expression } \\
\text { in transgenic cotton causes increased fiber length. }\end{array}$ & {$[64-66]$} \\
\hline $\begin{array}{l}\text { Ghi.8087.1. } \\
\text { S1_S_at }\end{array}$ & $\begin{array}{l}\text { myb-like transcription } \\
\text { factor } 3\end{array}$ & 1.32 & $\underline{0.18}$ & $\underline{0.16}$ & $\begin{array}{l}\text { GhMYB3, contains gibberellin responsive GLABROUS1, which } \\
\text { promotes trichome formation in A. thaliana. }\end{array}$ & {$[67,68]$} \\
\hline $\begin{array}{l}\text { Ghi.10822.1. } \\
\text { S1_at }\end{array}$ & $\begin{array}{l}\text { xyloglucan } \\
\text { endotransglucosylase } \\
\text { hydrolase }\end{array}$ & 1.10 & $\underline{0.41}$ & 0.52 & $\begin{array}{l}\text { GhXTH2, high homology to coding region of GhXTH1 which } \\
\text { produces longer fibers when over-expressed in transgenic cotton. }\end{array}$ & {$[69]$} \\
\hline $\begin{array}{l}\text { GraAffx.28354.1. } \\
\text { S1_s_at }\end{array}$ & $\begin{array}{l}\text { rho gtpase activation } \\
\text { protein }\end{array}$ & 0.52 & $\underline{0.48}$ & 0.78 & $\begin{array}{l}\text { High homology to ROP1, tip-localized GTPase responsible for cell } \\
\text { elongation and polarity. }\end{array}$ & {$[70]$} \\
\hline
\end{tabular}

*Bold and underlined indicates significant at the Bonferroni-corrected 0.05 probability level for microarray data.

not shown) although differential regulation between WT and the $L i_{1}$ mutant was not significant.

\section{Mapping the $L i_{1}$ locus region with SSR markers}

Of the 2,553 F2 progeny, 1,604 showed the $\mathrm{Li}_{1}$ mutant phenotype, and 949 were WT. This segregation deviated significantly from a single dominant-gene model $\left(\chi^{2}=605\right)$ presumably due to the failure of many homozygous mutants (which had deformed stems and leaves with stunted plants) to germinate or survive as suggested by Rong et al. [32] and Liu et al. [73]. Of the 921 SSR markers screened, $12(1.3 \%)$ were polymorphic between two DNA bulks. Of them, 7, 3, 1, and 1 were previously mapped on Chr.22, Chr.19, Chr.4 and Chr.5, respectively based on the high density consensus map [44]. Analysis of these 12 markers among 96 F2 progeny indentified only 5 markers that were associated with the $L i_{1}$ locus, and mapped on Chr.22. These 5 markers were further evaluated in the whole 2553 $\mathrm{F}_{2}$ progeny plants. A map was constructed around the $L i_{1}$ region (Figure 4). The marker TMB2500 was $0.8 \mathrm{cM}$ away from the $L i_{1}$ locus.

A total of $13 \mathrm{~kb}$ sequences from the introns of 23 genes residing in the $17 \mathrm{Mb}$ interval between markers TMB2500 and DPL0489 were compared between the WT and $L i_{1}$ 


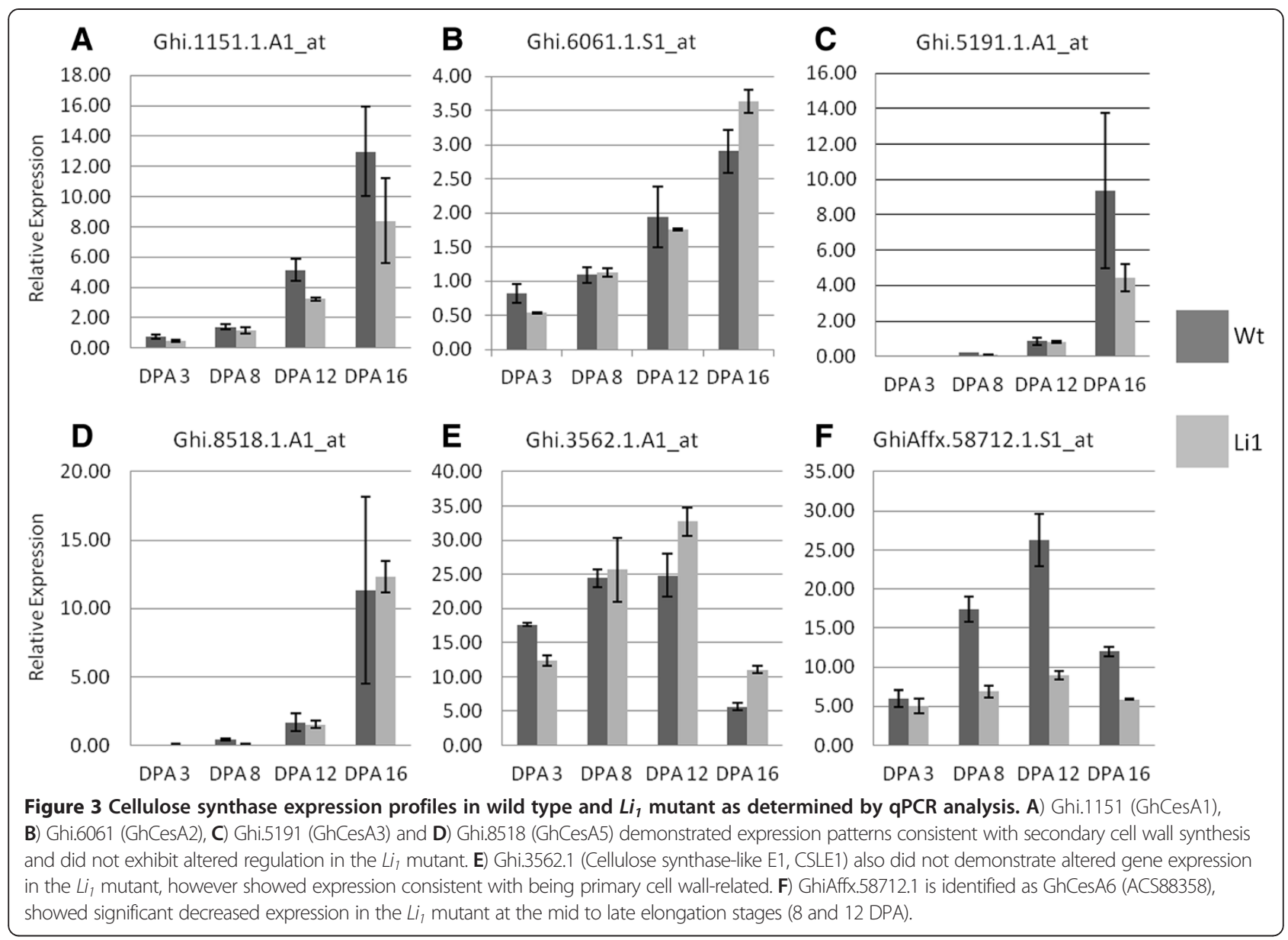

mutant. However, we were unable to identify additional sequence polymorphisms to facilitate finer genetic mapping of the $L i_{1}$ locus.

\section{Functional analysis of the $L i_{1}$ region}

Based on the mapping results, genes within the $17-\mathrm{Mb}$ region between the best hits of the flanking SSR markers TMB2500 and DPL0489 in the G. raimondii reference genome were further analyzed. Eighty probe sets from the microarray corresponded to genes that were in this interval, of which 24 showed altered expression in the $L i_{1}$ mutant (Additional file 7). Three of these genes were further evaluated by $\mathrm{qPCR}$ analysis to establish a link between the mapping and expression data. Ghi.10603.1.S1_s_at, GraA ffx.27319.1.S1_s_at, GhiAffx.1589.25.S1_s_at have homology with glycosyl hydrolase family protein $38(\mathrm{E}=5 \mathrm{e}-103)$,

Table 3 Microarray expression ratios of $L i_{1} / \mathrm{WT}$ and corroboration by RT-qPCR analysis*

\begin{tabular}{|c|c|c|c|c|c|c|c|}
\hline & & \multicolumn{2}{|l|}{ 3DPA } & \multicolumn{2}{|l|}{ 12DPA } & \multicolumn{2}{|l|}{ 16DPA } \\
\hline & & Micro-array & RT-qPCR & Micro-array & RT-qPCR & Micro-array & RT-qPCR \\
\hline GhiAffx.58712.1.S1_at & cellulose synthase catalytic subunit & 0.93 & $\underline{0.84}$ & $\underline{0.39}$ & 0.34 & $\underline{0.51}$ & $\underline{0.49}$ \\
\hline Ghi.3562.1.A1_at & cellulose synthase-like protein e6-like & $\underline{0.49}$ & 0.70 & $\underline{1.17}$ & 1.32 & $\underline{2.24}$ & 1.94 \\
\hline Ghi.5057.1.S1_s_at & protein wax2 & 0.47 & 0.41 & 0.59 & 0.46 & $\underline{0.42}$ & 0.29 \\
\hline Ghi.6485.1.S1_s_at & pathogenesis-related protein 10 & 1.34 & 1.51 & $\underline{70.42}$ & $\underline{127.01}$ & $\underline{77.04}$ & $\underline{191.91}$ \\
\hline Gra.3004.2.S1_s_at & expansin a10 & 0.82 & 0.82 & $\underline{0.46}$ & $\underline{0.38}$ & $\underline{0.46}$ & 0.33 \\
\hline Ghi.6465.2.S1_at & expansin-like b1 & 0.99 & 0.40 & $\underline{6.32}$ & $\underline{6.74}$ & 10.12 & 0.37 \\
\hline Gra.2056.1.A1_s_at & beta-galactosidase 13 & $\underline{0.23}$ & $\underline{0.12}$ & $\underline{0.09}$ & $\underline{0.05}$ & $\underline{0.17}$ & 0.11 \\
\hline Ghi.1314.1.S1_x_at & Tubulin alpha 4 (Tua 4) & 0.91 & 0.57 & 0.88 & 0.49 & 1.02 & 0.80 \\
\hline
\end{tabular}

*Bold and underlined indicates significant at the Bonferroni-corrected 0.05 probability level for microarray data and at the 0.05 probability as determined by a two-tailed t-test for qPCR data. 


\section{Chr22}

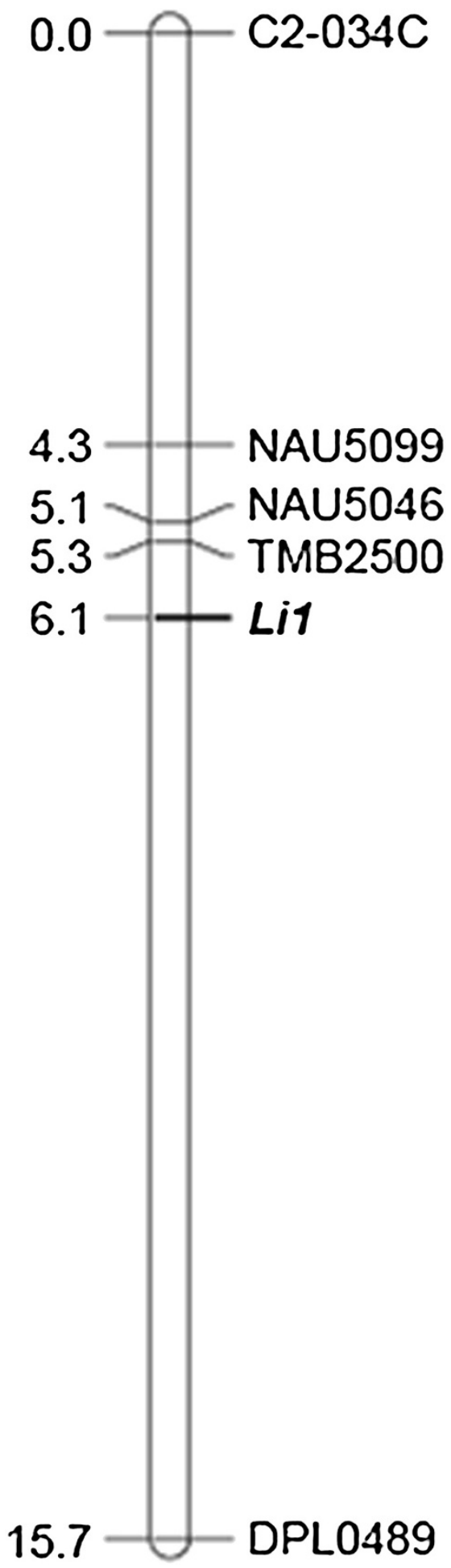

Figure 4 Linkage map of $L i_{1}$ genetic locus region on Chr. 22 . The distances (cM) are indicated on the left of the map and marker names on the right. xyloglucan endotransglucosylase/hydrolase $32(E=5 e-150)$, and AtTCP20 $(\mathrm{E}=1 \mathrm{e}-42)$, respectively. The expression profile of the glycosyl hydrolase 38 showed altered expression in the mutant at 16 DPA by both microarray and qPCR (Figure 5). Xyloglucan endotransglucosylase was upregulated at early and mid elongation stages (3 DPA and 8 DPA), and according to the microarray data remained slightly elevated at $12 \mathrm{DPA}$. The transcription factor TCP-20 was up-regulated at the late elongation stage of $12 \mathrm{DPA}$ and 16 DPA.

\section{Discussion}

A previous microarray experiment examining 0 and 3 DPA fibers from the $L i_{1}$ mutant found little evidence of global or significant alterations in gene expression patterns [27]. Conversely, microarray data of 6 DPA fibers and proteomic analysis of 12 DPA from $L i_{1}$ fibers demonstrated significant perturbation of expression profiles in the mutant, indicating that processes related to primary cell wall elongation are affected in the $L i_{1}$ mutant [27,29]. In addition, earlier studies of the $L i_{1}$ mutant focusing on secondary cell wall synthesis failed to report findings of upstream processes being significantly affected [28]. Thus this analysis on late elongation and early SCW stages would complement and extend these earlier findings aimed to better characterize the effects of the mutation at both primary and secondary cell wall synthesis, and provide data for the fiber development during the transition period. The morphological and molecular data presented here supports the model that the $L i_{1}$ mutation is an upstream factor primarily targeting elongation processes. Several ontological categories of genes and individual genes that have previously been identified as having a role in fiber elongation were identified, as were new targets for investigation.

Previous proteomic analysis of $L i_{1}$ at 12 DPA [29] identified a limited number of proteins that could be corroborated by our microarray data. A comprehensive analysis revealed that both data sets include the down regulation of cytoskelatal tubulin proteins and metabolism-related proteins (ie. glycolipid transfer protein and a pyrophosphatase). The stress response proteins nucleoredoxin and germin-like proteins, a flavanone-3-hydroxylase and translation factor 6 were increased in both data sets. However, the remainder of proteins identified as showing altered regulation were not corroborated by our data. A detail list is shown in the Additional file 8. This could be due to the difference in genetic background, or due to the technical limitations of 2-dimensional gel electrophoresis. Analysis of more recent Affymetrix microarray data obtained at 6 DPA [27] is limited by the fact that the authors did not provide probe set information, thus preventing a more rigorous or comprehensive analysis from being conducted. However, they also identified several actin and tubulin 


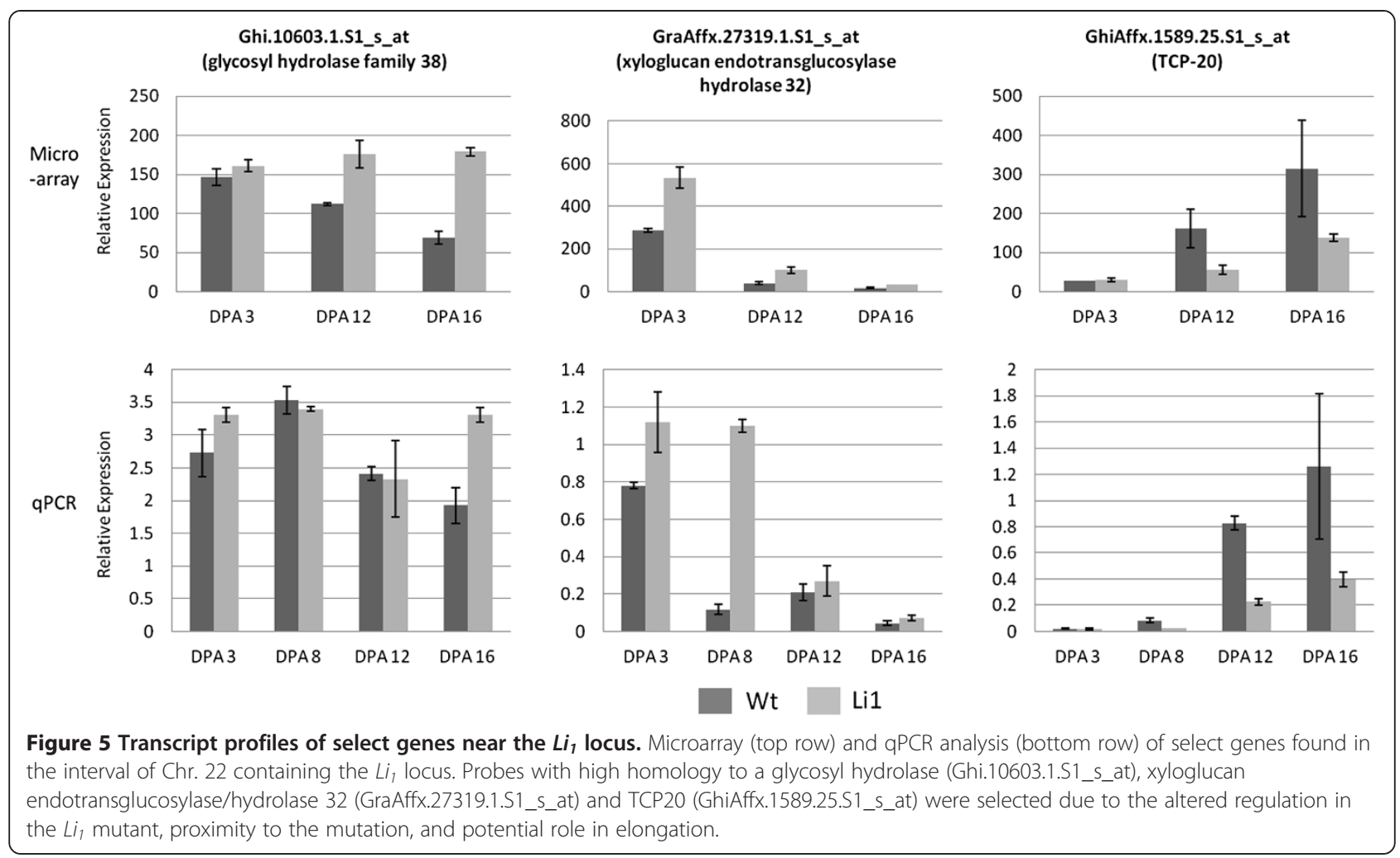

genes that were down-regulated in the mutant. At 6 DPA there was an increase in xyloglucan endotransglucosylase, fascilin-like arabinogalactan protein, and the ethylene synthesis-related 1-aminocyclopropane -1-carboxylate oxidase (GhACO3) which our data indicated remained true at 12 DPA. As expected several differences also exist. Analysis of 6 DPA fibers showed decrease expression levels of auxinIAA-related genes and the ethylene responsive AP2/ERF family genes, which then became up-regulated in the mutant at 12 DPA. Conversely, another gene involved in ethylene production, GhACO4, was up-regulated at 6 DPA but down-regulated in the mutant at 12 DPA. Genes that were down-regulated in $L i_{1}$ at $6 \mathrm{DPA}$, but were at WT levels in 12 DPA were enriched in plasma membrane associated proteins (GO:0005886, $\mathrm{p}=0.0008$ ), such as filament-like plant protein 4 , myosin heavy chain, and perk1-like protein kinase.

The use of the $L i_{1}$ mutant as a model system for both elongation and secondary cell wall synthesis was based on earlier studies utilizing $L i_{1}$ in a TM-1 genetic background that measured the ratio of fiber weight to length and showed an increase in fiber mass throughout development, implicating continued or increased cellulose deposition [18]. Despite its very short fibers, the authors claimed the dry mass of the $L i_{1}$ fiber was approximately $83 \%$ of its NIL. A second study using the same genetic line that measured $\left[{ }^{14} \mathrm{C}\right]$ glucose deposition in the secondary cell wall indicated a 5 -fold higher rate of cellulose deposition per $\mathrm{mm}$ of fiber in the $L i_{1}$ mutant [30]. However, much of our data using $L i_{1}$ in a DP5690 genetic background suggested that molecular events involved in cellulose deposition and secondary cell wall synthesis were not affected to the degree that primary cell wall processes were. Measurements indicated that the dry mass of the fiber was approximately $20 \%$ of its NIL and that the actual cellulose content per unit mass remained unchanged (Figure 1B). Further, qPCR of cellulose synthase genes showed that secondary cell wall genes remained largely unaffected. These results support the model that thickening of the cell wall is due to inhibited elongation processes, but not due to increased cellulose production. The "increased rate" of glucose incorporation observed by Kohel et al. [30] was based on measurements of cellulose production per unit length instead of per unit mass. However, since elongation ceases in the $L i_{1}$ mutant but its cellulose production continues at WT levels, we speculate that $L i_{1}$ fibers expand outwardly, thus resulting in an increased cellulose production per unit length. It is worthy to mention that the use of a different NIL in our study as compared with previous studies may also account for differences in fiber measurements.

The ontological categories of the 434 unique probes differentially expressed at 12 DPA included Xyloglucan: xyloglucosyl transferase activity (GO:0016762) (Table 1). Xyloglucan endotransglycosylase/hydrolase (XTH) enzymes 
are proposed to disrupt xyloglucan-cellulose crosslinks, thus permitting cell wall rearrangement and fiber elongation [48]. Six probe sets identified as XTH showed differential regulation in the $L i_{1}$ mutant. One probe set (Ghi.7911.1) was down-regulated at 3 DPA and significantly up-regulated (9 fold) at 12 DPA and 16 DPA (Additional file 6). This gene [GenBank:AY476737] remains uncharacterized in Gossypium, however its homeologous gene in $A$. thaliana TCH4/XTH22 (TAIR;AT5G57560) demonstrated very similar results in a study conducted on petiole elongation that indicated XTH22 is under different genetic regulation than other characterized XTH's [74]. Of the remaining XTHs identified in our microarray data, three probe sets exhibited decreased expression at $12 \mathrm{DPA}$ and one slightly increased. While it is clearly plausible that a decreased expression of XTHs could lead to the inhibition of elongation, the role of XTHs that increased in the $L i_{1}$ mutant warrants further investigation. Other ontological categories affected in the mutant included "responses to hormone synthesis" (GO:0009725) (ie. IAA synthetase and auxin-response genes) and "hydrolase activity, hydrolyzing O-glycosyl compounds" (GO:0004553), which contain 19 probe sets likely correlated with hormonal activation to signal entry into the primary to secondary cell wall transition stage [75]. The role of IAA, auxin response genes, and hormonal regulatory enzymes such as glucosyltranferases in fiber development processes has been widely documented [75]. It is of interest to note here that the only category identifying this set of related genes was the list of probes that were up or down-regulated only at 12 DPA. Probe sets that were also enriched or decreased in 16 DPA mutant tissues (Additional file 5) were not enriched in these ontological categories, implying that altered hormonal regulation in the mutant was occurring primarily before and at 12 DPA. Analysis of hormone contents by Chen et al. [76] identified altered levels of Abscisic Acid, dihydrozeatin, and others in the $L i_{1}$ mutant, but only analyzed up to 8 DPA. Microarray data on 6 DPA fibers reported altered expression of several hormone related peptides in the $L i_{1}$ mutant, such as auxin-related genes, gibberellins, brassinosteroid, abscisic acid and jasmonic acidrelated genes [27]. These data suggest, when taken together with molecular and morphological data, that the early cessation of elongation in $L i_{1}$, is in part due to the culmination of altered hormonal factors that occurs during early to mid elongation.

Consistent with what has been reported at earlier developmental stages, multiple genes related to ethylene biosynthesis and ethylene response were differentially expressed in the $L i_{1}$ fibers [27]. A key enzyme in ethylene biosynthesis, 1-aminocyclopropane-1-carboxylate synthase (ACS), hybridized by probe set Ghi.5451and demonstrated a 2-fold down-regulation at 12 DPA (Table 2). Previous studies have correlated increased ACS activity with cotton fiber elongation [54]. 1-aminocyclopropane-1-carboxylate oxidases (ACO) 1-4 are also involved in ethylene biosynthesis [54]. ACO3 (Ghi.798.1) showed a significant up-regulation at all stages analyzed, and ACO4 (Ghi.8025.1) exhibited down-regulation at $12 \mathrm{DPA}$ and 16 DPA. ACO1 and ACO2 (Ghi.6953.1 and Gra.2141.1, respectively) did not show altered expression in the $L i_{1}$ mutant. Consistent with our data, previous studies have implicated $A C O 3$ as having peak expression at the late elongation stage near 12 DPA. ACO1 and 2 have demonstrated different expression patterns with peak expression in early secondary cell wall synthesis stage $[54,55]$, implying that they may be involved in later developmental stages. The fact that $A C O 3$ was related to elongation in previous studies and showed altered regulation in our microarray (in contrast to ACO1 and 2) further supports $L i_{1}$ being a key elongation-related mutation.

Pathogenesis-related protein 10 family of proteins (PR10) exhibited a significant alteration in their expression patterns in the $L i_{1}$ mutant, ranging from 8 to 96 fold difference between $L i_{1}$ and WT. This family of proteins consists of a large and functionally diverse group of proteins, ranging in function from antimicrobial/antiviral activity, hormone/ligand binding, secondary metabolism, and abiotic stress response (reviewed in [77]). Further implying a role in growth and development, individual PR10 proteins have been found to be regulated by multiple phytohormone-related cis-regulatory sequences including ethylene response elements [78] and brassinosteroids [79]. However it remains unclear if the stress response seen in the $L i_{1}$ is related to previously mentioned ROS levels or a response to altered hormone expression.

The cellulose synthase activity reported here is of particular interest. Previous reports have speculated that an increase in secondary cell wall cellulose synthase activity may account for the thickened cell wall of the $L i_{1}$ [30], however, our data failed to confirm this. Rather, another GhCes, probed by Ghi.58712, demonstrated altered expression at the elongation stage of development and showed an expression pattern consistent with elongation-related activity in the WT. Translation of the probe target's consensus sequence and TAIR blast search showed the Ghi.58712 target sequence shared highest homology, although not identity with AtCesA9,-2,-5, -6 and $-3(\mathrm{E}=0.0)$. Atces $A 9$ is only expressed during embryogenesis, however the remaining AtCesA2, $-5,-6$, and -3 are members of a primary cell wall associated cellulose synthase complex (CSC) [72,80]. Substantial evidence exists that these closely related genes are cell elongation related. Atces 2 null mutations showed a severe dwarf phenotype in $A$. thaliana, and functional studies have demonstrated that AtCesA2 and -6 were partially functionally redundant during elongation [80]. A. thaliana mutants at the PROCUST1 locus, which encodes cesA6, exhibited cell elongation effects in a pleiotropic manner 
[81]. cesA6 promoter-GUS fusion experiments have demonstrated that its expression occurs throughout the hypocotyl and root, peaking in the cell elongation zone of the expanding root [72].

The $L i_{1}$ genetic locus was previously identified as residing on chromosome 22 [31,32]. Our results confirmed this chromosomal assignment. Based on the high density consensus genetic map constructed by Blenda et al. [44], it could be seen that the $L i_{1}$ locus might be close to the centromeric region as original indicated by Rong et al. [32]. It is worthy of mention that the genetic distances observed in our experiment were larger than those reported by Rong et al. [32]. This greater recombination observed in our research might be due to our much larger (151 vs 2,553) population size and different population structure (interspecific $v s$ intraspecific cross). There is a large gap $(9.6 \mathrm{cM})$ between the $L i_{1}$ locus and marker DPL0489 (Figure 4). We have screened all the SSR markers mapped in this interval based on the high density consensus map [44] and a newly published map [82], and could not further close the gap. Additionally, we were unable to identify sequence polymorphisms among the 23 gene introns that were located in the region harboring the $L i_{1}$ locus even though some of these genes demonstrated differential expression between WT and mutant. This also indicates that altered gene expression may not be necessary due to gene sequence change. This result may also imply that the genomic region harboring $L i_{1}$ locus is highly monomorphic. Recently, Cai et al. [20] reported a similar phenomenon when mapping the Lix locus. One of their flanking markers, NAU3469, was $24.5 \mathrm{cM}$ away from the Lix locus.

The mapping data coupled with the recently released G. raimondii sequences provided the opportunity for additional analysis of sequences in the vicinity of the $L i_{1}$ locus. Probe sets from the microarray with high homology to a glycosyl hydrolase family 38, a xyloglucan endotrans-glucosylase hydrolase 32, and AtTCP-20 are near the $L i_{1}$ locus, demonstrated differential expression in the $L i_{1}$ mutant and have apparent associations with elongation processes. In addition to the already discussed XTH enzymes, glycosyl hydrolase family 38, a family of related mannosidases, affect cell wall phenotypes when mutated in $A$. thaliana [83]. Interference with AtTCP-20 in planta in A. thaliana by fusion with a repressor domain resulted in severe developmental phenotypes characterized by reduced cellular elongation [84]. Additionally, a transcription factor identified in Gossypium barbadense with a highly homologous TCP domain, GbTCP, produced a short fiber phenotype when silenced by RNAi [85].

Determining which, if any of these is the $L i_{1}$ mutation is currently under investigation. Next-generation sequencing of transcripts by RNA-seq is currently under way in our laboratory, and may reveal SNPs or splice variants responsible for either altered regulation of an elongationspecific gene, or a mutation resulting in a nonfunctional protein. Identification of these variations will facilitate developing closer markers, and help to eventual cloning of the $L i_{1}$ gene.

The identification of the gene responsible for the $L i_{1}$ phenotype would provide an invaluable tool in the quest to understand fiber elongation processes. In the meantime, the data generated here, in combination with published data from other developmental time points, has the potential to provide a sound basis for the examination of key hormonal, structural, and other pathways involved in cotton fiber elongation.

\section{Conclusions}

Measurements of fiber characteristics and microarray analysis of the $L i_{1}$ mutant and its WT were conducted at 3,12 , and 16 DPA with the goal of enhancing our understanding of cotton fiber elongation. Both methodologies supported the notion that the early cessation of elongation in $L i_{1}$ was due to disruption of primary cell wall elongation-related processes. Further, we identified and discussed several elongation-related genes that exhibited altered expression profiles in the $L i_{1}$ mutant, including a putative primary cell-wall related cellulose synthase. We conducted SSR marker analysis on a large population, and using the G. raimondii reference sequence identified elongation-related genes near the $L i_{1}$ locus with altered expression levels. The data here will contribute to developing a comprehensive understanding of cotton fiber elongation.

\section{Availability of supporting data}

The data sets supporting the results of this article are included within the article and its Additional files.

\section{Additional files}

\footnotetext{
Additional file 1: Pedigree of the Li1 mutant and WT NILs. $L i_{7} L i_{7}$ and $\mid i_{7} l i_{7}$ were created using a $G$. hirsutum pure inbred cv. DP5690 backcrossed for 5 generations to a $\mathrm{F}_{1}$ generation DP5690/Li .

Additional file 2: qPCR Primer Sequences. Primer sequences used for quantitative PCR analysis.

Additional file 3: $L i_{1} L i_{1}, L i_{1} l i_{1}$ and $l i_{1} l i_{1}(\mathrm{WT})$ plants. Image of wild type (DP5690) (left), a heterozygous $L i_{7} / l i_{7}$ plant (center) and homozygous ( $L i_{1} /$ $L i_{7}$ ) (right) grown in standard field conditions and harvested five months after planting.

Additional file 4: Distribution of cell wall-related genes based on microarray data. The relative distribution of elongation, primary cell wall and secondary cell wall related probe sets and there relative expression in the $L i_{7}$ mutant in the developmental stages analyzed.

Additional file 5: Gene Ontology Enrichment Analysis for probe sets unique to 12 and 16 DPA. Gene Ontology Enrichment Analysis for the probe sets that show altered regulation in both 12 DPA and 16 DPA fibers but exclude 3 DPA.
} 
Additional file 6: Putative fiber-related probe sets and microarray data. List of putative fiber-related genes that show altered expression in the $L i$, mutant at 3,12 , and 16 DPA.

Additional file 7: Microarray results for targeted genes near the $L i_{1}$ locus. List of probe sets showing altered expression in the $L i$, mutant that were determined to be near the $L i_{1}$ locus.

Additional file 8: Transcript comparison between the present research and prior studies. List of probe sets that were identified in prior studies and their status in the present research.

\section{Abbreviations}

CSC: Cellulose synthase complex; DOA: Day of anthesis; DPA: Days postanthesis; EST: Expressed sequence tag; GOEA: Gene ontology enrichment analysis; IVT: In-vitro transcription; NIL: Near-isogenic line; PCW: Primary cell wall; RFLP: Restriction fragment length polymorphism; RT-qPCR: Reverse transcription quantitative polymerase chain reaction; SCW: Secondary cell wall; SNP: Single nucleotide polymorphism; SSR: Simple sequence repeat; TM-1: Texas Marker 1; WT: Wild type.

\section{Competing interests}

The authors declare that they have no competing interests.

\section{Authors' contributions}

DDF conceived the experiment, coordinated and supervised the research, identified molecular markers and conducted linkage mapping. MKG had the main responsibility for the study including the field work, tagging and sample harvest; RNA isolations and assessment of RNA quality; gene selection for corroboration of the microarray results: RT-qPCR and statistical analysis of the RT-qPCR data; and analyzing the microarray results. RBT developed the $L i_{1}$ mutant and WT NILs and the $F_{2}$ mapping population used as plant materials. HJK conducted fiber measurements and cellulose synthase assays. PL assisted with the molecular marker analysis. GT and MN assisted in sequence analysis. YT performed statistical analysis on the microarray data. CDD conducted fiber imaging analysis. MKG and DDF wrote the manuscript. All authors read and approved the final manuscript.

\section{Acknowledgments}

This research was funded by United States Department of AgricultureAgricultural Research Service CRIS project 6435-21000-016-00D. We greatly thank Mr. Chris Florane and Mrs. Tracy Condon for their assistance with field work, sample collection, and fiber structure analysis. We thank Mrs. Holly King for her expertise in fiber sectioning and imaging. Our great appreciation goes to Mrs. Sheron Simpson and Dr. Brian Scheffler at Genomics and Bioinformatics Research Unit at Stoneville, MS for their excellent support in SSR marker analysis. Mention of trade names or commercial products in this article is solely for the purpose of providing specific information and does not imply recommendation or endorsement by the U. S. Department of Agriculture that is an equal opportunity provider and employer.

\section{Author details}

${ }^{1}$ Cotton Fiber Bioscience Research Unit, USDA-ARS, Southern Regional Research Center, New Orleans, LA 70124, USA. ${ }^{2}$ Crop Genetics Research Unit, USDA-ARS, Mid South Area, Stoneville, MS 38772, USA. ${ }^{3}$ The Samuel Roberts Noble Foundation, Genomics Core Facility, Ardmore, OK 73401, USA. ${ }^{4}$ Cotton Structure and Quality Research Unit, USDA-ARS, Southern Regional Research Center, New Orleans, LA 70124, USA.

Received: 27 March 2013 Accepted: 12 June 2013

Published: 17 June 2013

\section{References}

1. Lee JJ, Woodward AW, Chen ZJ: Gene expression changes and early events in cotton fibre development. Ann Bot 2007, 100(7):1391-1401.

2. Basra AS, Malik CP: Development of the cotton fiber. Int Rev Cytol 1984, 89:65-113.

3. Tiwari SC, Wilkins TA: Cotton (Gossypium hirsutum) seed trichomes expand via diffuse growing mechanism. Can J Bot 1995, 73(5):746-757.
4. Meinert MC, Delmer DP: Changes in biochemical composition of the cell wall of the cotton fiber during development. Plant Physiol 1977, 59(6):1088-1097

5. Kim HJ, Triplett BA: Cotton fiber growth in planta and in vitro. Models for plant cell elongation and cell wall biogenesis. Plant Physiol 2001, 127(4):1361-1366.

6. Schubert AM, Benedict CR, Berlin JD, Kohel RJ: Cotton fiber development kinetics of cell elongation and secondary wall thickening. Crop Sci 1973, 13(6):704-709

7. Hinchliffe DJ, Meredith WR, Delhom CD, Thibodeaux DP, Fang DD: Elevated growing degree days influence transition stage timing during cotton fiber development resulting in increased fiber-bundle strength. Crop Sci 2011, 51:1683-1692.

8. Willison JH, Brown RM: An examination of the developing cotton fiber: wall and plasmalemma. Protoplasma 1977, 92(1-2):21-42.

9. Seagull RW: Changes in microtubule organization and wall microfibril orientation during in vitro cotton fiber development: an immunofluorescent study. Can J Bot 1986, 64(7):1373-1381.

10. Ruan $Y L$ : Recent advances in understanding cotton fibre and seed development. Seed Science Research 2005, 15(4):269-280.

11. Liakatas A, Roussopoulos D, Whittington WJ: Controlled-temperature effects on cotton yield and fibre properties. J Agric SCi 1998, 130(4):463-471.

12. Roussopoulos D, Liakatas A, Whittington WJ: Controlled-temperature effects on cotton growth and development. J Agric Sci 1998, 130(4):451-462.

13. Davidonis $\mathrm{GH}$, Johnson $\mathrm{AS}$, Landivar JA, Fernandez CJ: Cotton fiber quality is related to boll location and planting date. Agron J 2004, 96(1):42-47.

14. Turley RB, Kloth RH: Identification of a third fuzzless seed locus in upland cotton (Gossypium hirsutum L.). J Hered 2002, 93(5):359-364.

15. Ji SJ, Lu YC, Feng JX, Wei G, Li J, Shi YH, Fu Q, Liu D, Luo JC, Zhu YX: Isolation and analyses of genes preferentially expressed during early cotton fiber development by subtractive PCR and CDNA array. Nucleic Acids Res 2003, 31(10):2534-2543.

16. Wang QQ, Liu F, Chen XS, Ma XJ, Zeng HQ, Yang ZM: Transcriptome profiling of early developing cotton fiber by deep-sequencing reveals significantly differential expression of genes in a fuzzless/lintless mutant. Genomics 2010, 96(6):369-376.

17. Lee JJ, Hassan OS, Gao W, Wei NE, Kohel RJ, Chen XY, Payton P, Sze SH, Stelly DM, Chen ZJ: Developmental and gene expression analyses of a cotton naked seed mutant. Planta 2006, 223(3):418-432.

18. Kohel R, Quisenberry JE, Benedict CR: Fiber elongation and dry weight changes in mutant lines of cotton. Crop Sci 1974, 14:471-475.

19. Kohel RJ, Narbuth EV, Benedict CR: Fiber development of Ligon lintless-2 mutant of cotton. Crop Sci 1992, 32(3):733-735.

20. Cai C, Tong X, Liu F, Lv F, Wang H, Zhang T, Guo W: Discovery and identification of a novel Ligon lintless-like mutant (Lix) similar to the Ligon lintless (Li1) in allotetraploid cotton. Theor Appl Genet 2013, 126(4):963-970.

21. Wu Y, Machado AC, White RG, Llewellyn DJ, Dennis ES: Expression profiling identifies genes expressed early during lint fibre initiation in cotton. Plant and Cell Physiology 2006, 47(1):107-127.

22. Wu Y, Llewellyn DJ, White R, Ruggiero K, Al-Ghazi Y, Dennis ES: Laser capture microdissection and CDNA microarrays used to generate gene expression profiles of the rapidly expanding fibre initial cells on the surface of cotton ovules. Planta 2007, 226(6):1475-1490.

23. Kohel RJ: Linkage tests in Upland cotton, Gossypium hirsutum L. II. Crop Science 1972, 12:66-69.

24. Narbuth EV, Kohel RJ: Inheritance and linkage analysis of a new fiber mutant in cotton. J Hered 1990, 81:131-133.

25. Hinchliffe DJ, Turley RB, Naoumkina M, Kim HJ, Tang Y, Yeater KM, Li P, Fang DD: A combined functional and structural genomics approach identified an EST-SSR marker with complete linkage to the Ligon lintless-2 genetic locus in cotton (Gossypium hirsutum L.). BMC Genomics 2011, 12:445.

26. Naoumkina M, Hinchliffe DJ, Turley RB, Bland JM, Fang DD: Integrated metabolomics and genomics analysis provides new insights into the fiber elongation process in Ligon lintless-2 mutant cotton (Gossypium hirsutum L.). BMC Genomics 2013, 14:155.

27. Liu K, Sun J, Yao L, Yuan Y: Transcriptome analysis reveals critical genes and key pathways for early cotton fiber elongation in Ligon lintless-1 mutant. Genomics 2012, 100(1):42-50. 
28. Bolton JJ, Soliman KM, Wilkins TA, Jenkins JN: Aberrant expression of critical genes during secondary cell wall biogenesis in a cotton mutant, Ligon Lintless-1 (Li-1). Comp Funct Genomics 2009:Article ID 659301

29. Zhao PM, Wang LL, Han LB, Wang J, Yao Y, Wang HY, Du XM, Luo YM, Xia GX: Proteomic identification of differentially expressed proteins in the Ligon lintless mutant of upland cotton (Gossypium hirsutum L.). J Proteome Res 2010, 9(2):1076-1087.

30. Kohel RJ, Benedict $C R$, Jividen $G M$ : Incorporation of $\left({ }^{14} \mathrm{C}\right)$ glucose into crystalline cellulose in aberrant fibers of a cotton mutant. Crop Sci 1993 33(5):1036-1040.

31. Karaca M, Saha S, Jenkins JN, Zipf A, Kohel R, Stelly DM: Simple sequence repeat (SSR) markers linked to the Ligon lintless (Li1) mutant in cotton. $J$ Hered 2002, 93(3):221-224.

32. Rong J, Pierce GJ, Waghmare VN, Rogers CJ, Desai A, Chee PW, May OL, Gannaway JR, Wendel JF, Wilkins TA, et al: Genetic mapping and comparative analysis of seven mutants related to seed fiber development in cotton. Theor App/ Genet 2005, 111(6):1137-1146.

33. Updegraff DM: Semi-micro determination of cellulose in biological materials. Anal Biochem 1969, 32(3):420-424

34. Boylston EK, Thibodeaux DP, Evans JP: Applying microscopy to the development of a reference method for cotton fiber maturity. Textile Res J 1993, 63(2):80-87.

35. Taliercio EW, Boykin D: Analysis of gene expression in cotton fiber initials. BMC Plant Biol 2007, 7:22

36. Brazma A, Hingamp P, Quackenbush J, Sherlock G, Spellman P, Stoeckert C Aach J, Ansorge W, Ball CA, Causton HC, et al: Minimum information about a microarray experiment (MIAME)-toward standards for microarray data. Nat Genet 2001, 29(4):365-371.

37. Benedito VA, Torres-Jerez I, Murray JD, Andriankaja A, Allen S, Kakar K, Wandrey M, Verdier J, Zuber H, Ott T, et al: A gene expression atlas of the model legume Medicago truncatula. The Plant Journal 2008, 55(3):504-513

38. Du Z, Zhou X, Ling Y, Zhang Z, Su Z: agriGO: a GO analysis toolkit for the agricultural community. Nucleic Acids Res 2010, 38:W64-W70.

39. Conesa A, Gotz S, Garcia-Gomez JM, Terol J, Talon M, Robles M: Blast2GO: a universal tool for annotation, visualization and analysis in functional genomics research. Bioinformatics 2005, 21(18):3674-3676.

40. Persson S, Wei H, Milne J, Page GP, Somerville CR: Identification of genes required for cellulose synthesis by regression analysis of public microarray data sets. Proc Natl Acad Sci U S A 2005, 102(24):8633-8638.

41. Paterson AH, Wendel JF, Gundlach H, Guo H, Jenkins J, Jin D, Llewellyn D, Showmaker KC, Shu S, Udall J, et al: Repeated polyploidization of Gossypium genomes and the evolution of spinnable cotton fibres. Nature 2012, 492(7429):423-427.

42. Obayashi T, Nishida K, Kasahara K, Kinoshita K: ATTED-II Updates: conditionspecific gene coexpression to extend coexpression analyses and applications to a broad range of flowering plants. Plant and Cell Physiology 2011, 52(2):213-219.

43. Fang DD, Xiao J, Canci PC, Cantrell RG: A new SNP haplotype associated with blue disease resistance gene in cotton (Gossypium hirsutum L.). Theor App/ Genet 2010, 120(5):943-953.

44. Blenda A, Fang DD, Rami J-F, Garsmeur O, Luo F, Lacape J-M: A high density consensus genetic map of tetraploid cotton that integrates multiple component maps through molecular marker redundancy check. PLOS One 2012, 7(9):e45739.

45. Rong J, Abbey C, Bowers JE, Brubaker CL, Chang C, Chee PW, Delmonte TA, Ding X, Garza JJ, Marler BS, et al: A 3347-locus genetic recombination map of sequence-tagged sites reveals features of genome organization, transmission and evolution of cotton (Gossypium). Genetics 2004, 166(1):389-417.

46. Yu JZ, Kohel RJ, Fang DD, Cho J, Van Deynze A, Ulloa M, Hoffman SM, Pepper AE, Stelly DM, Jenkins JN, et al: A high-density simple sequence repeat and single nucleotide polymorphism genetic map of the tetraploid cotton genome. G3, Gene|Genome|Genetics 2012, 2(1):43-58.

47. Van Ooijen JW: JoinMap 4.0: Software for the calculation of genetic linkage maps in experimental populations. Wageningen, The Netherlands: Kyazma B.V; 2006.
48. Shao MY, Wang XD, Ni M, Bibi N, Yuan SN, Malik W, Zhang HP, Liu YX, Hua $\mathrm{SJ}$ : Regulation of cotton fiber elongation by xyloglucan endotransglycosylase/hydrolase genes. Genet Mol Res 2011, 10(4):3771-3782

49. Thaker VS, Saroop S, Singh YD: Physiological and biochemical changes associated with cotton fibre development. IV. Glycosidases and $\beta-1,3$ glucanase activities. Ann Bot 1987, 60(5):579-585.

50. Li J, Nam KH, Vafeados D, Chory J: BIN2, a new brassinosteroid-insensitive locus in Arabidopsis. Plant Physiol 2001, 127(1):14-22.

51. Evans ML: The action of auxin on plant cell elongation. CRC Crit Rev Plant Sci 1985, 2(4):317-365.

52. Murphy MP: How mitochondria produce reactive oxygen species. Biochem J 2009, 417(1):1-13.

53. Wang X, Zhang Y, Zhang J, Cheng C, Guo X: Molecular characterization of a transient expression gene encoding for 1-aminocyclopropane-1carboxylate synthase in cotton (Gossypium hirsutum L.). J Biochem Mol Biol 2007, 40(5):791-800

54. Wang H, Mei W, Qin Y, Zhu Y: 1-Aminocyclopropane-1-carboxylic acid synthase 2 is phosphorylated by calcium-dependent protein kinase 1 during cotton fiber elongation. Acta Biochem Biophys Sin (Shanghai) 2011, 43(8):654-661.

55. Shi YH, Zhu SW, Mao XZ, Feng JX, Qin YM, Zhang L, Cheng J, Wei LP, Wang $Z Y$, Zhu YX: Transcriptome profiling, molecular biological, and physiological studies reveal a major role for ethylene in cotton fiber cell elongation. Plant Cell 2006, 18(3):651-664.

56. Hare PD, Moller SG, Huang LF, Chua NH: LAF3, a novel factor required for normal phytochrome A signaling. Plant Physio/ 2003, 133(4):1592-1604

57. Li J, Yu M, Geng L- L, Zhao J: The fasciclin-like arabinogalactan protein gene, FLA3, is involved in microspore development of Arabidopsis. The Plant Journal 2010, 64:482-497.

58. Chen YH, Yang XY, He K, Liu M, Li J, Gao Z, Lin ZQ, Zhang Y, Wang X, Qiu X, et al: The MYB transcription factor superfamily of Arabidopsis: expression analysis and phylogenetic comparison with the rice MYB family. Plant Mol Biol 2006, 60(1):107-124.

59. Padmalatha KR, Patil DP, Kumar K, Dhandapani G, Kanakachari M, Phanindra ML, Kumar S, Mohan TC, Jain N, Prakash AH, et al: Functional genomics of fuzzless-lintless mutant of Gossypium hirsutum L. Cv. MCU5 reveal key genes and pathways involved in cotton fibre initiation and elongation. BMC Genomics 2012, 13:624.

60. Cernac A, Andre C, Hoffmann-Benning S, Benning C: WRI1 is required for seed germination and seedling establishment. Plant Physiol 2006, 141(2):745-757.

61. Brill E, van Thournout M, White RG, Llewellyn D, Campbell PM, Engelen S, Ruan Y, Arioli T, Furbank RT: A novel isoform of sucrose synthase is targeted to the cell wall during secondary cell wall synthesis in cotton fiber. Plant Physiol 2011, 157(1):40-54.

62. Takahashi N, Nakazawa M, Shibata K, Yokota T, Ishikawa A, Suzuki K, Kawashima M, Ichikawa T, Shimada H, Matsui M: shk1-D, a dwarf Arabidopsis mutant caused by activation of the CYP72C1 gene, has altered brassinosteroid levels. The Plant Journal 2005, 42(1):13-22.

63. Qin YM, Hu CY, Pang Y, Kastaniotis AJ, Hiltunen JK, Zhu YX: Saturated verylong-chain fatty acids promote cotton fiber and Arabidopsis cell elongation by activating ethylene biosynthesis. Plant Cell 2007, 19(11):3692-3704

64. Frigerio M, Alabadi D, Perez-Gomez J, Garcia-Carcel L, Phillips AL, Hedden P, Blazquez MA: Transcriptional regulation of gibberellin metabolism genes by auxin signaling in Arabidopsis. Plant Physiol 2006, 142(2):553-563.

65. Cowling RJ, Harberd NP: Gibberellins control Arabidopsis hypocotyl growth via regulation of cellular elongation. J Exp Bot 1999, 50(337):1351-1357.

66. Xiao YH, Li DM, Yin MH, Li XB, Zhang M, Wang YJ, Dong J, Zhao J, Luo M, Luo $X Y$, et al: Gibberellin 20-oxidase promotes initiation and elongation of cotton fibers by regulating gibberellin synthesis. J Plant Physio/ 2010, 167(10):829-837.

67. Loguerico LL, Zhang JQ, Wilkins TA: Differential regulation of six novel MYB-domain genes defines two distinct expression patterns in allotetraploid cotton (Gossypium hirsutum L.). Mol Gen Genet 1999, 261(4-5):660-671.

68. Perazza D, Vachon G, Herzog M: Gibberellins promote trichome formation by Up-regulating GLABROUS1 in arabidopsis. Plant Physiol 1998, 117(2):375-383. 
69. Lee J, Burns TH, Light G, Sun Y, Fokar M, Kasukabe Y, Fujisawa K, Maekawa $Y$, Allen RD: Xyloglucan endotransglycosylase/hydrolase genes in cotton and their role in fiber elongation. Planta 2010, 232(5):1191-1205.

70. Hwang JU, Vernoud V, Szumlanski A, Nielsen E, Yang Z: A tip-localized RhoGAP controls cell polarity by globally inhibiting Rho GTPase at the cell apex. Curr Biol 2008, 18(24):1907-1916.

71. Seo PJ, Lee AK, Xiang F, Park CM: Molecular and functional profiling of Arabidopsis pathogenesis-related genes: insights into their roles in salt response of seed germination. Plant Cell Physiol 2008, 49(3):334-344.

72. Desprez T, Juraniec M, Crowell EF, Jouy H, Pochylova Z, Parcy F, Höfte H, Gonneau M, Vernhettes S: Organization of cellulose synthase complexes involved in primary cell wall synthesis in Arabidopsis thaliana. Proc Natl Acad Sci USA 2007, 104(39):15572-15577.

73. Liu FJ, Liang WH, Zhang TZ: Genetic analysis of homozygous-dominant -surviving ligon lintless recombinants in cotton (Gossypium hirsutum L.). Acta Agronomica Sinica 2010, 36(12):2020-2027.

74. Sasidharan R, Chinnappa CC, Staal M, Elzenga JT, Yokoyama R, Nishitani $K_{t}$ Voesenek LA, Pierik R: Light quality-mediated petiole elongation in Arabidopsis during shade avoidance involves cell wall modification by xyloglucan endotransglucosylase/hydrolases. Plant Physiol 2010, 154(2):978-990.

75. Sembdner G, Atzorn R, Schneider G: Plant hormone conjugation. Plant Mol Biol 1994, 26(5):1459-1481.

76. Chen J, Du X, Zhou X, Zhao H: Levels of cytokinens in the ovules of cotton mutants with altered fiber development. J Plant Growth Regul 1997, 16:181-185.

77. Liu J, Ekramoddoullah AK: The family 10 of plant pathogenesis-related proteins: their structure, regulation, and function in response to biotic and abiotic stresses. Physiol Mol Plant Pathol 2006, 68(1-3):3-13.

78. Liu J, Ekramoddoullah AK, Piggott N, Zamani A: Molecular cloning of a pathogen/wound-inducible PR10 promoter from Pinus monticola and characterization in transgenic Arabidopsis plants. Planta 2005, 221(2):159-169.

79. Markovic-Housley Z, Degano M, Lamba D, von Roepenack-Lahaye E, Clemens S, Susani M, Ferreira F, Scheiner O, Breiteneder H: Crystal structure of a hypoallergenic isoform of the major birch pollen allergen Bet $v 1$ and its likely biological function as a plant steroid carrier. J Mol Biol 2003, 325(1):123-133.

80. Persson S, Paredez A, Carroll A, Palsdottir H, Doblin M, Poindexter P, Khitrov $\mathrm{N}$, Auer M, Somerville CR: Genetic evidence for three unique components in primary cell-wall cellulose synthase complexes in Arabidopsis. Proc Natl Acad Sci USA 2007, 104(39):15566-15571.

81. Fagard M, Desnos T, Desprez T, Goubet F, Refregier G, Mouille G, McCann M, Rayon C, Vernhettes S, Hofte H: PROCUSTE1 encodes a cellulose synthase required for normal cell elongation specifically in roots and dark-grown hypocotyls of Arabidopsis. Plant Cell 2000, 12(12):2409-2423.

82. Zhao L, Lv Y, Cai C, Tong X, Chen X, Zhang W, Du H, Guo X, Guo W: Toward allotetraploid cotton genome assembly: integration of a highdensity molecular genetic linkage map with DNA sequence information. BMC Genomics 2012, 13:539.

83. Liebminger E, Huttner S, Vavra U, Fischl R, Schoberer J, Grass J, Blaukopf C, Seifert GJ, Altmann F, Mach L, et al: Class I alpha-mannosidases are required for $\mathrm{N}$-glycan processing and root development in Arabidopsis thaliana. Plant Cell 2009, 21(12):3850-3867.

84. Herve C, Dabos P, Bardet C, Jauneau A, Auriac MC, Ramboer A, Lacout F, Tremousaygue D: In vivo interference with AtTCP20 function induces severe plant growth alterations and deregulates the expression of many genes important for development. Plant Physiol 2009, 149(3):1462-1477.

85. Hao J, Tu L, Hu H, Tan J, Deng F, Tang W, Nie Y, Zhang X: GbTCP, a cotton TCP transcription factor, confers fibre elongation and root hair development by a complex regulating system. J Exp Bot 2012, 63(17):6267-6281.

doi:10.1186/1471-2164-14-403

Cite this article as: Gilbert et al:: Transcript profiling by microarray and marker analysis of the short cotton (Gossypium hirsutum L.) fiber mutant Ligon lintless-1 $\left(L i_{1}\right)$. BMC Genomics 2013 14:403.

\section{Submit your next manuscript to BioMed Central and take full advantage of:}

- Convenient online submission

- Thorough peer review

- No space constraints or color figure charges

- Immediate publication on acceptance

- Inclusion in PubMed, CAS, Scopus and Google Scholar

- Research which is freely available for redistribution
C Biomed Central 